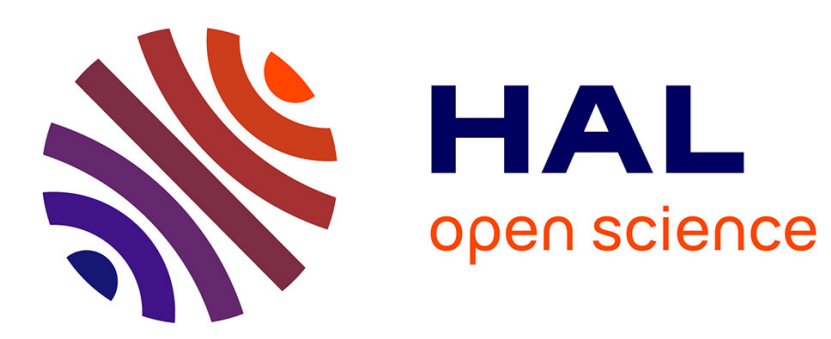

\title{
Collaboration in the digital age: From email to enterprise social networks
}

Emmanuel Bertin Orange, Aubin Colleaux, Aurélie Leclercq Vandelannoitte

\section{To cite this version:}

Emmanuel Bertin Orange, Aubin Colleaux, Aurélie Leclercq Vandelannoitte. Collaboration in the digital age: From email to enterprise social networks. Systèmes d'Information et Management, 2020, 10.3917/sim.201.0007 . hal-03328166

\section{HAL Id: hal-03328166 https://hal.science/hal-03328166}

Submitted on 28 Aug 2021

HAL is a multi-disciplinary open access archive for the deposit and dissemination of scientific research documents, whether they are published or not. The documents may come from teaching and research institutions in France or abroad, or from public or private research centers.
L'archive ouverte pluridisciplinaire HAL, est destinée au dépôt et à la diffusion de documents scientifiques de niveau recherche, publiés ou non, émanant des établissements d'enseignement et de recherche français ou étrangers, des laboratoires publics ou privés. 


\title{
Collaboration in the digital age: From email to enterprise social networks
}

\author{
Emmanuel BERTIN \\ Orange, France
}

Aubin COLLEAUX

Pernod Ricard, France

Aurélie LECLERCQ-VANDELANNOITTE

CNRS - LEM (UMR CNRS 9221), IESEG School of Management, Univ. Lille, F-59000

Lille, France

\begin{abstract}
A revolutionary medium of communication in the 1990s, email has progressively revealed its limitations and even emerged as a source of information overload. In response, many companies have adopted enterprise social networks (ESN) as alternative communication channels, though surprisingly little research attention focuses on the articulation process by which both technologies influence work practices, through complementarity or substitution effects, or addresses the information overload challenge. In this article, we detail an empirical, qualitative study of the articulations of emails, ESN, and other collaborative tools in organizations, on the basis of 1) an exploratory study of three companies from various sectors, 2) an auto-ethnography that relies on participant observations from a large French telecommunication company, and 3) a validation through in-depth discussions with experts. The resulting causal framework of the articulations of usage factors of email, ESN, and specialized collaborative tools at work contains three main contributions. First, we enhance understanding of information overload by clarifying that it is not intrinsic to email and by analyzing the emerging notion of "collaborative overload." Second, we determine that ESN may not be the solution for fostering new behaviors. Third, workplaces do not need ESN tooling but rather require a digital transformation strategy, with more emphasis on meeting employees' needs instead of focusing solely on an ESN's promise for altering workplace culture and practices.
\end{abstract}

\section{Keywords}

email; enterprise social network; collaboration; information overload; collaborative overload; digital transformation strategy. 


\section{Collaborer à l'ère du numérique : de l'email aux réseaux sociaux d'entreprise?}

\section{Résumé :}

Alors qu'il était perçu comme un moyen de communication révolutionnaire dans les années 1990, l'email a progressivement montré ses limites...si bien qu'il est devenu une source de surcharge informationnelle. Afin d'adresser ce problème, de nombreuses organisations ont adopté des réseaux sociaux d'entreprise (RSE) comme moyens de communications alternatifs. De façon surprenante, peu de recherches se sont penchées jusqu'à aujourd'hui sur le processus d'articulation de ces deux technologies et sur l'influence de cette articulation sur les pratiques de travail et le problème de la surcharge informationnelle, à travers l'analyse d'éventuels effets de complémentarité et/ou de substitution. Dans cet article, nous développons une étude empirique qualitative des articulations entre emails, RSE et autres outils collaboratifs, sur la base 1) d'une étude exploratoire de trois entreprises de secteurs variés, 2) d'une auto-ethnographie reposant sur une observation participante dans une grande entreprise de télécommunication française, et 3) d'une validation auprès d'experts. Le diagramme causal qui en résulte, permettant de spécifier l'articulation des usages de l'email, des RSE et des outils collaboratifs spécialisés, suggère trois principales contributions. Premièrement, nous développons notre compréhension du problème de surcharge informationnelle, en précisant que ce dernier n'est pas intrinsèque à l'email, et se voit de plus en plus remplacé par le concept émergent de «surcharge collaborative ». Deuxièmement, nous mettons en évidence que les RSE ne sont pas la panacée afin d'encourager de nouveaux comportements au sein de l'organisation. Troisièmement, nous mettons en exergue que les organisations ont moins besoin d'un outillage RSE que d'une stratégie de transformation digitale, mettant l'accent sur les besoins des collaborateurs, plutôt que sur la promesse des RSE de changer les cultures d'entreprises et pratiques.

\section{Mots-clés :}

email; réseau social d'entreprise; collaboration; surcharge informationnelle; surcharge; stratégie de transformation digitale. 


\section{Introduction}

According to Thierry Breton, CEO of the French telecommunications company Atos, speaking in 2011, "The volume of emails we send and receive is unsustainable for business.... Managers spend between five and 20 hours a week reading and writing emails.... Email is on the way out as the best way to run a company and do business." His comments align with broader evidence, which shows that 215 billion emails were sent in 2016 and an estimated 258 billion messages will be exchanged in 2020, even before we count spam (Orsys, 2017). Managers average five hours a day dealing with email (Orsys, 2017), and for two-thirds of Internet users, the first thing they do each day is check their electronic messages, after which $65 \%$ of them check emails about every five minutes (Laval, 2015). Thus $70 \%$ of emails are read within 6 seconds of their arrival (Addas and Pinsonneault, 2015). In the United States, $61 \%$ of employees surveyed called email "very important" to their professional activity, but $65 \%$ of employees also said the invasive effect of emails and the constant pressure to check for new messages caused them stress (Tarafdar et al., 2015; Stich et al., 2019). The proliferation and pervasiveness of mobile devices (Mazmanian et al., 2013) accentuates such changes in social behavior (Soror et al., 2015) and their negative side effects (Tarafdar et al., 2015). As national legislation in countries such as France and Germany seeks to protect employees' right to disconnect (Legifrance, 2016), the issues raised by email usage have grown vivid and highly salient. This time-consuming technology has developed a reputation as a key source of interruptions, frustration, unnecessary communication, and stress (Addas and Pinsonneault, 2018), limiting productivity and direct interactions - a stark contrast to its function as the backbone of organizational communication (Ayyagari et al., 2011; Tarafdar et al., 2015).

In response, more companies (e.g., Atos, Virgin) have started implementing enterprise social networks (ESN) (Burkus, 2016; Goodwin, 2014). Rather than focusing solely on communication, ESN constitute real work and productivity tools that aim to encourage collaborative practices and knowledge sharing in organizational contexts (Boukef et al., 2017a; Ellison et al., 2015; Turban et al., 2011). These online platforms combine multiple functions and tools (e.g., blogs, forums, wikis, profiles) to support collaboration and communication (Boyd and Ellison, 2007; Leonardi et al., 2013). Software companies have introduced ESN solutions, including major companies such as Microsoft (Yammer, Office 365) or Facebook (Workplace), as well as pure players like Jive Software. By providing means to unify communication flows, ESN might facilitate information sharing and break down classical organizational silos. As email overload becomes a growing concern (Sobotta, 2016), ESN concomitantly is emerging as a popular technology, and this trend has been reinforced by the entry of the latest generation to the labor market (Schwabel, 2014; Shirish et al., 2016). As his statement at the start of this article indicated, Thierry Breton's decision to replace internal emails with collaborative tools emerged from his perception of the communication needs of a new generation of workers. These developments predict a radical transformation, at the technological level but also and mostly at managerial and organizational levels, with vast potential impacts on managers' and employees' respective roles.

However, with few exceptions (Bertin and Alimam, 2016; Burkus, 2016; D'Anselme, 2014; Oettl et al., 2018; Silic et al., 2015; Shipilov and Crawford, 2015; Pillet and Carillo, 2016; Verdot et al., 2011), management information systems (MIS) research has not addressed how ESN could replace email or their articulation processes at work. Studies explore the use of social media (Stenger and Coutant, 2015; Boukef et al., 2017b; Mlaiki et al., 2017) but not ESN specifically (Leonardi et al., 2013; Treem and Leonardi, 2013) or its possible interaction with existing technologies. Instead, most research focuses on technological aspects 
(Mathiesen and Fielt, 2013). In general, MIS research has not addressed alternatives to email, such as dedicated collaborative tools, with the exception of a few case studies that report on experiments in specific sectors, such as collaborative software development (Dabbish et al., 2012; Lin et al., 2016) or medical epidemiology (Gofine and Clark, 2017). A gap thus persists, between organizations' needs and the lack of conceptual framing of the articulations of email and ESN. In response, this study establishes a central research question: How can we grasp the articulations between emails and ESN for purposes of collaboration in organizational contexts? This question is of substantial importance for IS researchers, especially in light of recent examples that highlight the practical difficulties of replacing email by ESN (Filippone, 2014; Oettl et al., 2018; Shirish et al., 2016).

We accordingly conduct an empirical, qualitative study of the articulation of emails and ESN in organizations. To start, we undertake a review of literature pertaining to the characteristics of emails and ESN and their relations, including implementation processes, achievements, issues, and possible articulations. Our empirical, longitudinal study relies on multiple sources (Pascal et al., 2018): an exploratory study based on semi-directive interviews conducted in three companies in different sectors, an auto-ethnography based on participant observations in a large French telecommunication company, and a validating discussion with a community of IT experts. The heterogeneous data sources help us acknowledge the rapid evolutions of our research object over time. To present our results, we then propose a causal diagram that frames the theoretical and practical implications we derive. Our contributions thus are threefold. First, we show that information overload is not a problem intrinsic to email. Second, ESN does not emerge as a "killer tool" for fostering new behaviors, because it creates another type of overload, stemming from demands for collaborative tasks in the evolving work conditions of the digital age. Third, the most important goal for organizations should not be "ESN tooling" but rather an overall "digital transformation strategy." Practitioners should assess specialized tools other than ESN, especially according to their ability to combine individual, team-wide, and community-wide objectives, while also directly supporting workers' daily tasks and business processes.

\section{Email: Whys and wherefores}

Although it represents a keystone of corporate communication, email suffers notable limitations, prompting an alternative view that refers to it as the bane of people's professional lives. The volume of internal emails has increased so much in the past two decades that firms have been forced to address a new organizational problem: email overload.

\section{The backbone of organizational communication}

Email facilitates communication through its inherent, unique characteristics (Derks and Bakker, 2010; Sproull and Kiesler, 1986; Thomas, 2006) as an asynchronous communication medium that is text based. By offering multiple addressability, email makes it easy for senders to add and drop multiple recipients of one message (Jackson et al., 1999; Kraut et al., 1997; Markus, 1994; McKeen and Smith, 2004); its "built-in memory" characteristic (Thomas, 2006) also allows messages to be externally recorded (Markus, 1994) and captured or forwarded (Kraut et al., 1997), enabling complex inbox management practices (Bellotti et al., 2005; Mackay, 1988; Whittaker and Sidner, 1996). Email lets users communicate regardless of the availability of recipients (Boukef and Kalika, 2002) or hierarchical constraints (Sproull and Kiesler, 1986). Finally, email users can communicate regardless of spatial and temporal constraints, a characteristic that has undergirded its success (Van Den Hooff et al., 2005). 
Because "the average office worker dips into their inbox about 11 times an hour, receives about 147 messages a day, and spends nearly $30 \%$ of their total working week in their inbox" (Glei, 2016), email has expanded to become more than a simple communication tool. Through the years, functionalities of email tools have become much broader than the initial ones, as defined for example by Sproull (1991). We have identified in the IS literature six main new functionalities in addition to the usual intrinsic email features (Table 1). For example, it supports task management (to recall a particular task context, to follow the progress of ongoing tasks, or to handle conflicts, Lee et al., 2018), personal archiving or filing (to deal with received messages, to store personal names and addresses) (Whittaker and Sidner, 1996), and document delivery and archiving (Adam, 2002; Zhu et al., 2006). By transferring attachments and work-related links, email also has become a primary document delivery method for personal computer users (Ducheneaut and Belotti, 2003). Because it can issue announcements (e.g., agendas, out-of-office notices, general announcements (Denis and Assadi, 2005), it can enhance commitment (Kraut et al., (1997), due to the simultaneity of exchanges it enables. In turn, especially when adopted on mobile devices, email provides organizing and coordinating (e.g., scheduling meetings), coauthoring and reviewing, information gathering (e.g., corporate form filing), and technical query (Whittaker and Sidner, 1996) support. Overall, it has transformed into a resource for organizational knowledge and memory (Stein and Zwass, 1995; Tran, 2010) that allows users to access past knowledge to support their current activities.

\begin{tabular}{|l|l|}
\hline \multicolumn{1}{|c|}{ Functionality } & \multicolumn{1}{c|}{ References } \\
\hline Task management & $\begin{array}{l}\text { Adam, 2002; Bellotti et al., 2005; Ducheneaut } \\
\text { and Bellotti, 2001; Mackay, 1988; Dabbish et } \\
\text { al., 2005; Barley et al., 2011; Tran, 2010; } \\
\text { Whittaker and Sidner, 1996; Zhu et al. 2006 }\end{array}$ \\
\hline Document delivery and archiving & $\begin{array}{l}\text { Adam, 2002; Denis and Assadi, 2005; } \\
\text { Ducheneaut and Bellotti, 2001, 2003; Zhu et al., } \\
2006\end{array}$ \\
\hline Personal archiving and filing & $\begin{array}{l}\text { Adam, 2002; Denis and Assadi, 2005; Tran, } \\
2010 ; \text { Whittaker and Sidner, 1996 }\end{array}$ \\
\hline Nearly synchronous communication & $\begin{array}{l}\text { Denis and Assadi, 2005; Tran, 2010; Renaud et } \\
\text { al., 2006 }\end{array}$ \\
\hline Organizing and scheduling & $\begin{array}{l}\text { Barley et al., 2011; Ducheneaut and Bellotti, } \\
2001 ; \text { Dabbish et al., 2005 }\end{array}$ \\
\hline Organizational knowledge and memory & $\begin{array}{l}\text { Denis and Assadi, 2005; Stein and Zwass, 1995; } \\
\text { Tran, 2010 }\end{array}$ \\
\hline
\end{tabular}

\section{Table 1: Email Functionalities}

Ducheneaut and Bellotti $(2001,2003)$ describe email systems as "habitats," where knowledge workers spend most of their working hours. This effective metaphor is even more applicable today, given the pervasiveness and ubiquity of mobile devices (Mazmanian et al., 2013).

\section{Negative effects of email use}

Practitioner studies and MIS research also highlight some negative outcomes of the excessive use of email (Tarafdar et al., 2015). The costs of using email usually are "loaded onto the recipient" (Renaud et al., 2006, p. 327), as manifested in the time they spend managing emails and the pressure they feel to respond almost immediately, which create excessive work and stress (Barley et al., 2011; Stich et al., 2019). The inherent qualities of email (ease and 
rapidity of use) make it simultaneously very useful and very dangerous for employees, for four main reasons.

First, email is easy and fast to use, so it has prompted massive increases in the exchange of written information (Rice, 1987; Thomas, 2006). Users must devote extra time to sorting and filing the messages, as well as to efforts to find necessary information (Osterman, 2008). The use of email also alters the way people communicate (Sarbaugh-Thompson and Feldman, 1998), resulting in a loss of greetings and real-time interactions (Osterman, 2014a), often to the detriment of affectively based relationships (Cudicio and Proulx, 2006).

Second, email makes it easier to request action, such that users are more likely to shift among tasks, which creates interruptions (Jackson et al., 2003), with potentially negative implications for productivity and work quality (Addas and Pinsonneault, 2015). Some estimates suggest that IT interruptions due to emails generate more than 70 work suspensions per day (Addas and Pinsonneault, 2015, p. 231), even though employees consider only a small proportion of them (15\% of received messages) to be relevant or useful.

Third, people lose time due to email program inadequacies (Barley et al., 2011; Bellotti et al., 2005), such as when they try to perform tasks that email systems originally were not designed to support (e.g., file transfer, storage). Even a large amount of exchanged emails might not provide enough information for recipients to act on the message (Frazee, 1996). This challenge is twofold: People increasingly shift between tasks, but they also lack the information to perform the new task, so they lose time trying to find it. The issue is exacerbated by the risk of misinterpretation (McKeen and Smith, 2004), in that email channels often fail to communicate accurate emotions (Byron, 2008), which can produce misunderstanding and conflict (Denis and Assadi, 2005).

Fourth, email offers a nearly synchronous medium of communication, and the speed of delivery creates a response expectation and underlying pressure on recipients (Renaud et al., 2006), referred to as the "recipient's burden" (Tyler and Tang, 2003). They must track whether they have responded to messages they have received in a timely way. They also need to set up notifications, screen out unwanted messages, and filter incoming messages. This synchronous mode, coupled with the expanded use of mobile devices, leads to communications outside working hours (Ayyagari et al., 2011; Capra et al., 2013), increasing stress, and connectivity dependence (Barley et al., 2011). According to Mazmanian et al. (2013, p. 1337), mobile email devices create an "autonomy paradox," such that enacting a "norm of continual connectivity and accessibility" produces contradictory outcomes. As a result, users feel overwhelmed by the volume of messages they receive, the pressure to respond quickly, and the difficulty of establishing an efficient filing strategy (Adam, 2002).

These components of "email overload" (Sobotta and Hummel, 2015; Sobotta, 2016) highlight the multifaceted nature of this issue. Excessive uses can lead to overload, though it also depends on personal perspectives (Konstant and Taylor, 2009; McKeen and Smith, 2004). Ayyagari et al. (2011) identify email "technostress" that arises in response to technology characteristics (e.g., intrusiveness) coupled with inherent work stressors (e.g., work overload, role ambiguity). Although there is no universal definition of email overload, it is often associated with information overload (Forsyth and Jenkins, 2009). We address whether email is a cause or a medium of this general notion of information overload in Section VI. Overload implies an excess of information (Mungly and Singh, 2012), marked by poor accessibility (i.e., people cannot find the right information) and fragmentation (i.e., information is spread across too many sources, channels and people; Janseen and De Poot, 2006). Email overload in particular is characterized by ambiguous requests (Thomas et al., 2006) that make it hard to decide which actions are required, as well as cascades due to the use of "cc" or "reply all" 
options (Janseen and De Poot, 2006). When people use email as a task management or personal storage tool, it adds to the clutter in in-boxes (Adam, 2002; Ducheaneaut and Watts, 2005). Thus email overload results partially because people use their email for more tasks than it was originally designed to support, and they feel they do not control the information flow (Whittaker and Sidner, 1996). It also arises because users do not feel in control of information flows, such as when processing requirements are greater than processing capacities (Forsyth and Jenkins, 2009). Users then cannot handle communications appropriately or promptly (McKeen and Smith, 2004), and they wind up sending and receiving "more emails than they can handle, find and process effectively" (Dabbish and Kraut, 2006, p. 431).

Companies thus face a dilemma: Knowledge workers receive too much information but not enough accurate information (Edmunds and Morris, 2000). Email overload results in failed searches, duplication of work, a lack of authoritative content, and lost opportunities, which in turn lower people's ability to process information, make decisions, and prioritize tasks (Speier et al., 1999; Spira, 2011). Email recipients suffer more stress (Stich et al., 2019) and lower productivity, which can hinder organizational performance (Forsyth and Jenkins, 2009; Fredd et al., 2008). We list some of the consequences of email overload in Table 2, including decreased message quality, loss of information, poor retention (Huber and Daft, 1987), task switching (Jackson et al., 1999; 2003), impaired judgment, technostress, and compulsive behaviors (Tarafdar et al., 2015; Turel et al., 2011; Soror et al., 2012; Steelman et al., 2012).

\begin{tabular}{|l|l|}
\hline \multicolumn{2}{|c|}{ Consequences of email overload on employees and organizations } \\
\hline Lower ability to process information & (Spira, 2011; Shenk, 1998; Speier et al., 1999) \\
\hline $\begin{array}{l}\text { Mental and psychological issues (like stress, } \\
\text { technostress, compulsive behaviors, and low job } \\
\text { satisfaction) }\end{array}$ & $\begin{array}{l}\text { (Forsyth and Jenkins, 2009; Janseen and De } \\
\text { Poot, 2006) Ayyagari et al., 2011; Tarafdar et } \\
\text { al., 2014, 2015; Turel et al., 2011; Soror et al., }\end{array}$ \\
\hline Low quality decision-making process & (Isaac et al., 2008; Mungly and Singh, 2012) \\
\hline Decreased job performance & $\begin{array}{l}\text { (Forsyth and Jenkins, 2009; Dabbish and Kraut, } \\
\text { 2006; Fredd et al., 2008; Butcher, 1998) }\end{array}$ \\
\hline $\begin{array}{l}\text { Extra time required to search, sort and process } \\
\text { information }\end{array}$ & (Spira, 2011) \\
\hline
\end{tabular}

\section{Table 2: Consequences of Email Overload}

To address such issues, some strategies have proven useful (Forsyth and Jenkins, 2009), such as filtering, which also can cause users to miss important information; filing (Barley et al., 2011; Bellotti et al., 2005; Whittaker and Sidner, 1996); or managing interruptions by turning off email alerts, for example (Jackson et al., 2003). A skill-based approach suggests the need for education, training, and sharing information handling best practices (Addas and Pinsonneault, 2015, 2018). For example, practice communities allow workers to share their experiences and encourage better practices. A lack of training instead increases email overload (Dawley and Anthony, 2003). Another option is to define communication procedures better. At Bouygues Telecom, emails may not include more than three recipients (Tran, 2010); other companies more generally encourage synchronous and oral communication to resolve problems (Harnish, 2014). Intel has implemented "no email days" and formal agreements about acceptable response time frames (Spira, 2011). However, even if these solutions help reduce email overload, some companies continue to seek to overcome email limitations by implementing new tools, such as ESN. 


\section{ESN: Alternative to email?}

Replacing emails with more modern and collaborative IT, such as ESN, to address the email overload problem is gaining popularity. Social networks already have invaded personal spheres (Stenger and Coutant, 2015), and they increasingly appear in corporate settings too. The adoption of ESN is reinforced by new IT usages embraced by young workers in Generations Y and Z, who largely have replaced personal emails with social networks, such that they enter the labor market with distinct expectations of IT uses (Chandra et al., 2012; Fraser and Dutta, 2010; Schwabel, 2014; Shirish et al., 2016). To grasp the interactions and articulations between emails and ESN, we first define ESN and present their main functions, then analyze the main issues at stake in their implementation.

\section{Definition and main functions of ESN}

The constant evolution of social media platforms has made it difficult to establish definitions of either social media or ESN. Broadly though, social media are online platforms that allow users to create, access, share, and modify content and interact (Avram, 2006; Kaplan and Haenlein, 2010; Stenger and Coutant, 2015; Mlaiki et al., 2017). Social media platforms generally provide seven functionalities, referred to as their "honeycomb" (Kietzmann et al., 2011): presence (instant conversations); relationship (connection with others); identity (specifying the user's profile); reputation (determining social standing of content and other users); communications (enabling communication); and sharing (enabling the exchange and diffusion of content).

The terms social media and social networks are often used interchangeably, but social networks constitute a specific segment of social media (Zubac and Petrov, 2013). A social network site thus refers to an online service with three main purposes: creation of an online profile, connection with other users within the system, and searches for connections among users (Boyd and Ellison, 2007). An ESN more specifically refers to an online platform that offers a combination of functions and tools, such as blogs, forums, and wikis, along with social features such as profiles (Leonardi et al., 2013). This assembly of separate applications (e.g., instant messaging, wikis, status updates) gets integrated within larger collaborative platforms that can increase employees' productivity and collaboration, and thus corporate revenues (Stephens, 2013). As a defining characteristic, ESN are not organized in silos but rather proactively seek to establish ties between users through conversation (Poinsot et al., 2010) and enable them to work toward a common objective, similar to project teams. DiMicco et al. (2009, p. 1) describe ESN as "designed to support employees within an enterprise in connecting and learning about each other through personal and professional sharing." To that end, ESN generally enable four activities: interacting with colleagues through written or vocal messages; grouping with peers to share similar interests or work on projects; posting, editing and classifying documents; and searching for information (Leonardi et al., 2013; Becker, 2013). Communication, knowledge management, problem solving, training and learning, collaboration and innovation, and information dissemination and sharing are key functionalities targeted by ESN (Turban et al., 2011; Ellison et al., 2015).

In turn, organizations resort to ESN for various reasons (Leonardi et al., 2013). First, ESN may create value by enhancing communication, internal and external collaboration, knowledge sharing, and expert input on specific business topics (McKinsey Global Institute, 2012). For example, adopting ESN makes knowledge access $25 \%$ faster (Maan, 2012). In these informal relations, conversations also tend to focus on outputs and value creation (Cudicio and Proulx, 2006). Second, ESN might improve decision-making processes and prompt employees to be more flexible and responsive to the current business environment 
(Maan, 2012). The resulting increases to overall organizational productivity are estimated to be between 25\% and 30\% (McKinsey Global Institute, 2012; Maan, 2012). Third, ESN favor mobility (Maan, 2012), allowing a broader distribution of the workforce (Datchary, 2005) while still keeping employees connected and engaged (Gallup, 2013). In particular, ESN make it easy to collaborate and communicate regardless of time, geographical, or hierarchical barriers (Burton et al., 2010; Silva and Ben Ali, 2010). They can facilitate access to senior management and evoke changes in corporate culture, because communications and collaboration tend to be more open and transparent. Fourth, ESN should increase employees' satisfaction, engagement, and retention, particularly among digital natives (Martin and Van Bavel, 2013) who already are willing to use such platforms.

One of the main goals of an ESN implementation is to reduce email overload or even replace email to some extent, by allowing collaboration and communication tasks to take place through the ESN instead of through email. Through restructuring work and making communication flows more fluid and efficient, ESN promote wider information and knowledge sharing and thus may help professionals manage information exchanges and communications (Riemer et al., 2012). Günther et al. (2009) recognize the potential of microblogging to mitigate email overload, by avoiding issuing the same email multiple times to different receivers. Especially in light of evidence that knowledge workers much of their work time emailing and tracking down information (McKinsey Global Institute, 2012), practitioner studies and ESN vendors propose using collaborative platforms to reduce email usage and thus solve the overload problem. Both technologies offer similar features and fulfill the same functions (Table 3), so ESN arguably could effectively replace email and solve the email overload problem, as suggested by the case of Atos (Burkus, 2016; D'Anselme, 2014; Oettl et al., 2018; Shipilov and Crawford, 2015; Silic et al., 2015).

\begin{tabular}{|l|l|l|}
\hline \multicolumn{1}{|c|}{ Functionalities } & \multicolumn{1}{c|}{ Email } & \multicolumn{1}{c|}{ ESN } \\
\hline Task management & $\begin{array}{l}\text { Yes (e.g., built-in task } \\
\text { management application) }\end{array}$ & $\begin{array}{l}\text { Yes (e.g., built-in task } \\
\text { management application) }\end{array}$ \\
\hline $\begin{array}{l}\text { Document delivery and } \\
\text { archiving }\end{array}$ & $\begin{array}{l}\text { Yes (message delivered and stored } \\
\text { in mailbox or folders) }\end{array}$ & $\begin{array}{l}\text { Yes (document posted on the ESN } \\
\text { and persistently stored) }\end{array}$ \\
\hline $\begin{array}{l}\text { Personal archiving and } \\
\text { filing }\end{array}$ & Yes (e.g., folders) & $\begin{array}{l}\text { Yes (personal knowledge } \\
\text { management functions) }\end{array}$ \\
\hline $\begin{array}{l}\text { Synchronous } \\
\text { communication }\end{array}$ & $\begin{array}{l}\text { Yes (through nearly synchronous } \\
\text { communication and built-in } \\
\text { instant messaging function in } \\
\text { some tools) }\end{array}$ & Yes (instant messaging function) \\
\hline Organizing and scheduling & Yes (e.g., calendar tool) & $\begin{array}{l}\text { Yes (e.g., built-in organization } \\
\text { and scheduling application) }\end{array}$ \\
\hline $\begin{array}{l}\text { Organizational knowledge } \\
\text { and memory }\end{array}$ & Yes (at the individual level) & $\begin{array}{l}\text { Yes (through overall knowledge } \\
\text { management functions) }\end{array}$ \\
\hline Microblogging & No & Yes \\
\hline Tagging (notifications) & No & Yes (notifications) \\
\hline Wikis and forums & No & Yes \\
\hline
\end{tabular}

Table 3: Comparison of Email and ESN Functions

Some predictions indicate that email volume could fall by $20 \%$ (Richter et al., 2013), as a clear potential benefit of ESN usage (Martin and Van Bavel, 2013). McKinsey Global Institute (2012) finds that $80 \%$ of the Western companies surveyed planned to implement an 
ESN or had already done so, and among them, at least $30 \%$ claimed a goal of replacing or at least limiting the use of email.

For example, Atos famously implemented ESN in 2011 to replace internal email, foster innovation, and increase productivity (Becker, 2013). The implementation process raised many issues, as detailed by the company's CEO Thierry Breton:

We put on the table the fact that most of the young people that we were hiring were not using email anymore after graduating from universities. They were instead mainly using instant messaging tools and social networks like Facebook - and for most of them, when they joined Atos it was first time they had ever worked with internal email tools like [Microsoft] Outlook. So this intrigued me - and in addition I had already been thinking for many years that most of my colleagues and my employees were spending increasing amounts of time on internal emails.... So when we put all this together I started an in-depth study with our consulting practice to see how many internal emails the 80,000 employees of Atos were receiving. We found on average it was over 100 emails per day. After further analysis, we realized they found $15 \%$ of the messages useful, and the rest was lost time. But they had a fear that they would miss something. We checked at work and at home also-and we realized they were spending 15 to 20 hours a week checking and answering internal emails.... So we launched a team to investigate what sort of tools we could use to replace internal emails.... When we don't have internal email anymore we will have fantastic new tools - a cloud computing environment, social networks, instant messaging, micro blogging, document sharing, knowledge community - these offer a much better approach for an information technology company. My first intention was to deal with this internal data deluge and to work with the tools that the young generation are using.... When you believe that a new technology will replace another one, then you create some debate.

Source: http://www.bbc.com/news/technology-16055310, March 8, 2012

\section{Vignette 1: Concrete example of ESN replacing emails}

\section{Issues and challenges raised by ESN implementation}

Yet the Atos case also highlights that despite the great potential of ESN, implementation challenges have arisen, and the effective business value and performance improvements achieved through ESN use have yet to be proven (Miller et al., 2011; Oettl et al., 2018; Shirish et al., 2016; Skeels and Grudin, 2009). Few of the key objectives pursued with an ESN implementation actually have been met in reality (Altimeter Group, 2012; Oettl et al., 2018; Skeels and Grudin, 2009).

In particular, ESN might lower hierarchical barriers, by circumventing established communication processes (Cross et al., 2001; Subramaniam and Nandhakumar, 2013), but their implementation demands massive changes to the organizational structure (Burkhardt and Brass, 1990), for which organizations are not always ready. For example, Verra et al. (2012) find that ways of working did not transform radically following the implementation of an ESN. Companies instead have reported failed attempts to reduce internal emails and information overload, because of the difficulty involved in getting employees to adopt the ESN and change their work habits (Shirish et al., 2016).

Failures also emerge from the divergent perceptions of ESN across business units or managerial levels (Figueroa and Cranefield, 2012). When some users fail to find any business value of ESN, they regard them as wastes of time and financial investments ( $\mathrm{Li}$ and Bernoff, 
2011), which may prevent their adoption by other potential users. The implementation pattern (bottom-up or top-down) also determines the adoption process. In the current IT consumerization era, corporate adoptions of ESN often reflect a bottom-up logic (LeclercqVandelannoitte, 2015; McAfee, 2009), such that managers might not even be aware of the initiatives, meaning that they also cannot establish corporate strategies to ensure their success. Systems introduced by different users also may lack interoperability (Osterman, 2014b). In contrast, a top-down approach could produce an implementation process that does not reflect the needs of users, so they are unlikely to adopt the tool (Vaast, 2008).

These employees also face the growing challenge of working with a vast variety of devices, communication tools, and applications (Kalika et al., 2007), few of which work together (González and Mark, 2004). The lack of interoperability between ESN and other applications thus is a growing concern, especially considering that companies generally have made substantial investments to acquire the various technologies (Maan, 2012).

As additional influences, recent research suggests that a lack of privacy is a main driver of ESN non-adoption, especially among Generation Y employees (Shirish et al., 2016). Factors such as user perceptions of leadership styles, structural assurances, empowerment, and organizational justice also might determine the adaptive use of ESN (Chandra et al., 2012; Shirish et al., 2016).

To address such issues, MIS research offers some best practices (Silva and Ben Ali, 2010), such as training users, creating usage norms (Orlikowski et al., 1995), analyzing users' readiness to change and adoption costs, or developing consistent experiences (Osterman, 2014b). Notably, ESN adoption requires a clear strategic plan, metrics based on the return on investments, the integration of enterprise resources, and interoperability between the ESN and other applications (Maan, 2012). It is also important to "chase" information to highlight the value of ESN relative to other technologies (e.g., email) (Günther et al., 2009). Thus three categories of critical success factors emerge from prior research (Conley, 2013) for inscribing ESN initiatives in business strategy: the company (e.g., top management engagement, corporate and technological culture), change management skills and vision, a dedicated team that can nurture online communities and create a "digital village" (Anderson and Mohan, 2011; Fidelman, 2013; Poinsot et al., 2010), and the external environment that allows for the integration of suppliers and customers into the ESN.

Moving beyond the identification of best practices and critical determinants of the adoption process, the potential for ESN to replace email, as well as the interactions and articulations of these two tools, has not been explored. Most MIS studies take an overview of communication tools in organizations, such as investigating substitution between electronic and face-to-face communications (as suggested by millefeuille theory; Kalika et al., 2007). Such technologies and communication tools have distinct capabilities, functions, and goals, so they support different communication contexts (Daft and Lengel, 1986; Valacich et al., 1993), justifying their coexistence and concomitant use within organizations. But ESN and emails instead offer similar features and functions, so organizations need to consider substitution effects. The question of their possible articulation in turn becomes more pertinent.

Thus, as email overload concerns grow for organizations and ESN uses develop and gain popularity (D'Anselme, 2014; Oettl et al., 2018), the need arises to investigate the articulation of email and ESN usages at work. How do email and ESN usages articulate in work settings? How can we grasp their possible substitution and complementarity effects? To what extent can ESN replace internal email and solve the email overload problem? 


\section{Methodology}

We first describe the research design of this research, before describing the processes of data collection and data analysis.

\section{Research design}

With this article, we explore the uses of ESN in greater depth to determine whether it might provide a solution to the email overload problem. Our goal is not to specify the determinants of adoption or acceptance of ESN at work (as addressed by well-established technology acceptance models; e.g., Davis, 1989; Venkatesh and Davis 2000; Venkatesh et al. 2003) but rather to explore articulations and substitution and complementarity interactions between two technologies that can perform similar functions (Burkus, 2016; Goodwin, 2014). Because no prior academic research has investigated such interactions, we adopt an exploratory longitudinal qualitative research approach (Miles and Huberman, 1994) to pursue a deep understanding of this specific, understudied phenomenon. Our empirical study comprises multiple, heterogeneous data sources, gathered longitudinally to reflect the evolving nature of the research objects (email, ESN, and their articulations) and of our empirical questions (Pascal et al., 2018). Specifically, the investigation includes three steps (Table 4):

1. We conducted an exploratory study of three real business cases (Benbasat et al., 1987) that implemented ESN in fall 2014, to gain exploratory insights into its possible articulations and ability to replace email (Colléaux et al., 2017). In turn, we gained a better understanding of the relevance of our research questions in real business contexts and identified important common topics, issues, challenges, and divergences among the three exploratory cases.

2. One author conducted an in-depth, longitudinal case study in parallel, through participant observation at Spinach $\operatorname{Tech}^{1}$, a large telecommunications company that uses emails, a corporate ESN, and other collaborative tools. The researcher had worked for the company for more than 10 years as a senior communication services and IT architecture expert, in which role this researcher conducted both applied and academic research on the uses of emails and ESN. A longitudinal case study approach (Yin, 1994) provides rich, concrete descriptions of local phenomena (Miles and Huberman, 1994), in particular in MIS (Benbasat et al., 1987); the participant observation method (Girin, 1981) also supports the collection of rich and varied information from a detailed investigation within a company. Auto-ethnography gives voice to personal experiences, to extend sociological understanding (Wall, 2008), so this author adopted this method to write, retroactively and selectively, about his lived experience, such that it represents both a process and a product (Ellis et al., 2011). Combining these insights with our initial exploratory findings, we confronted our own findings, enriched our understanding of local causalities, and drew some conclusions about the articulations of email and ESN.

3. To ensure the empirical validity of our findings, we presented them to a panel of 15 IS experts (e.g., CIOs, IT project managers, digital officers of large French companies) during a seminar held in November 2017 at the Club Informatique des Grandes Entreprises Françaises (CIGREF). During this presentation, we discussed our findings and verified their empirical soundness with direct feedback from well-known experts who had confronted similar issues in their organizations.

\footnotetext{
${ }^{1}$ We use a pseudonym.
} 


\section{Data collection}

During the three steps, we collected different types of data, to achieve triangulation (Table 4). First, the exploratory study relied on semi-directive interviews conducted with representatives from three large French firms ${ }^{2}$ : PleinDénergie, operating in the energy sector; Banque Bonjour, a regional bank; and BelleCulture, an international chemical manufacturer. The selection of those firms reflected convenience criteria (which is acceptable for exploratory studies; Glaser and Strauss, 1967), yet they also were representative of the three different sectors, and they differed in the ESN they used, maturity, and characteristics. Banque Bonjour and PleinDénergie both relied on internal platforms, called Inca and PleinDénergie Online, respectively. Yammer, developed by Microsoft, provided a third-party solution for BelleCulture. To identify employees' uses of email and ESN, we conducted semi-structured interviews, for which we selected respondents using a snowball sampling method based on peer recommendations. We also sought profile diversity, defined according to client-facing and internal job roles, ages, and genders. A single researcher conducted 24 interviews during September and November 2014 ( 8 from Banque Bonjour, 7 from BelleCulture, and 9 from PleinDénergie) (Appendix 1), mostly face-to-face but also some via phone $(n=6)$ if the interviewees were away from the office. The interviews lasted about 45 minutes each and were recorded and then transcribed. Through these interviews, we particularly sought to understand the informants' uses of both email and ESN, the importance of those uses in the workplace, the articulation of their usages of both tools, and the factors influencing the potential replacement of email by ESN. The interview guide, prepared in advance, featured key topics derived from our literature review, but respondents also could express themselves freely, following an inductive logic. The interview guide also acknowledged the varying ESN and levels of maturity of the tools that the respondents might use. Thus every interview began with general questions about the respondent's role and preferred communication tools. They also indicated the amount and quality of information that passed through their hands every day. Further questions asked about the different functions of email and ESN, namely, to what extent they competed or overlapped. To uncover reasons for specific uses of email or ESN, the interviewer encouraged the respondents to think about different factors (e.g., personal habits, shared behavioral regularities and norms, corporate pressures). We also gathered internal documentation as secondary data to grasp the context of the exploratory case studies.

Second, our in-depth longitudinal case study relies on participant observation and autoethnography (Hayano, 1979); it was conducted in parallel by another author, working as a "researcher-actor," to enrich our exploratory study and compare findings. With this process, we collected detailed feedback about the articulations of emails and ESN according to an indepth, day-to-day analysis of their usages, opportunities, and limitations. Because our goal was to confirm, inform, and enrich the exploratory findings, we also considered uses of other collaborative tools. This participant observation was conducted at Spinach Tech, a large French company operating in the telecom and media domain, which began using an ESN in 2011. The longitudinal participant observation process took place from May 2015 to May 2017 , under the aegis of a larger research project on the use of emails in organizations. Thus, the researcher-actor could observe the evolution of the usages and articulations of the focal tools. This researcher-actor was completely integrated within the organization, as a senior expert working on IT uses and communication questions. This status was well received by other employees, especially because the research was presented as a means to reveal interesting uses and possible articulations of the tools, internally and more broadly. The collected material included field notes, observations, summaries of formal and informal

\footnotetext{
${ }^{2}$ Confidentiality was a prerequisite for conducting the interviews, so the names of the firms and their proprietary
} ESN have been changed. 
discussions, and meeting transcriptions, as well as a quantitative analysis of the use of the internal ESN, performed from May to July 2017.

Third, we presented the combined findings to a panel of 15 IT experts and CIOs, members of a renowned association gathering of 150 large French companies and public agencies (CIGREF). These IT experts represent France's French economic sectors well (banking, insurance, energy, retail, industry, services). This presentation occurred in November 2017, during a seminar designed to encourage encounters between researchers and practitioners. It was structured around a 30-minute presentation of our results, followed by a 60-minute question-and-discussion session. After these formal interactions, we conducted informal exchanges with the IT experts, who provided insightful feedback. We took careful notes during and directly after the discussions. The oral discussions and resulting notes informed the report that we wrote, which we also shared with all CIGREF members.

\begin{tabular}{|c|c|c|}
\hline Step & Goal & Data \\
\hline $\begin{array}{l}\text { 1: Exploratory } \\
\text { study of three real } \\
\text { business cases }\end{array}$ & $\begin{array}{l}\text { Initial exploratory insights into the } \\
\text { possible articulations of emails and } \\
\text { ESN; confirm the relevance of such } \\
\text { questions; identify important common } \\
\text { topics, issues, challenges, and } \\
\text { divergences across cases }\end{array}$ & $\begin{array}{l}24 \text { semi-directive interviews in } 3 \\
\text { companies: } 9 \text { in an energy company, } \\
8 \text { in a regional bank, } 7 \text { at an } \\
\text { international chemical manufacturer } \\
\text { Internal documentation }\end{array}$ \\
\hline $\begin{array}{l}\text { 2: Parallel, in-depth } \\
\text { longitudinal case } \\
\text { study in a large } \\
\text { French } \\
\text { telecommunications } \\
\text { company }\end{array}$ & $\begin{array}{l}\text { Compare the results and enrich, } \\
\text { confirm, infirm the exploratory } \\
\text { findings. Extend the questioning to } \\
\text { dedicated collaborative tools } \\
\text { Make long-term observations of the } \\
\text { evolution of the usages and potential } \\
\text { articulations of such tools. }\end{array}$ & $\begin{array}{l}\text { Longitudinal participant observation } \\
\text { by one author (auto-ethnography), } \\
\text { working in this company as a } \\
\text { researcher and expert on these topics, } \\
\text { from May } 2015 \text { to May } 2017\end{array}$ \\
\hline $\begin{array}{l}\text { 3: Validation of } \\
\text { results by a panel of } \\
\text { IT expert }\end{array}$ & $\begin{array}{l}\text { Ensure the empirical validity of the } \\
\text { findings }\end{array}$ & $\begin{array}{l}\text { Presentation and discussion of results } \\
\text { with } 15 \text { IT experts, in November } \\
2017 \text {. Writing and diffusion of an } \\
\text { official report. }\end{array}$ \\
\hline
\end{tabular}

Table 4: Synthesis of the Research Design and Collected Data

\section{Data analysis}

The collected materials (transcribed interviews, notes from observations, feedback from IT experts) were analyzed with a step-by-step thematic coding procedure in Excel. First, we coded data from the exploratory study. The interviews from Step 1 (exploratory case studies) were read carefully to identify common and resurgent topics, which suggest potential categories. We assigned codes to the different themes (nodes) emerging from the data and quickly identified four meaningful categories to represent the data: email perceived importance, functions, and uses; ESN perceived importance, functions, and uses; factors influencing the adoption and use of ESN over email; and articulations between email and ESN.

Second, we confronted these preliminary findings and the coding scheme with data collected in Step 2 through our longitudinal participant observation (field notes, observations, results of formal and informal discussions, meeting transcriptions). We adopted an abductive logic in this step (both deduction and induction), in that we applied the four categories derived from our exploratory study to code our data, searched for occurrences of such topics, and used the 
collected data to explore new relations and emerging topics (e.g., expressions of specific needs, recourse to alternative platforms, specific collaborative tools that support different tasks and distinct needs, emerging concept of "collaborative overload," overload management questions, the inscription of such tools in a "broader digital transformation strategy"). As we continued to categorize the data, we enriched the coding by identifying subcategories (subthemes) in several dimensions. We then cut and sorted them into an Excel file, such that we grouped the data according to their category, theme, or dimension (Appendix 2).

Third, we used the feedback from IT experts and written notes collected during the meeting, then coded the approved report (Step 3) according to these dimensions, to ensure the validity of our findings. Overall, this coding process helped us identify important relations and chains of causality in the interactions and articulations of ESN and email in work settings (Figure 1). To synthetize the results and present them analytically, in line with the objectives and scope of this research, we chose to develop a causality diagram, conceived of as "a network at the origin of an explicative proposition of observed situations" (Miles and Huberman, 1994, p. 234). That is, with our objective of understanding local causalities, by taking into account the analysis context (Yin, 1994), we considered a causal diagram particularly helpful and relevant. As Miles and Huberman (1994, p. 274) explain, "the causal diagram is a mental construction based upon a reality and likely to explain it. It is a visualization of the most important variables, more than of their correlation. It therefore is about a network originally of an explanatory proposition of observed situations." With this causal diagram, we group the main items and causal chains identified with our coding process, such that we can visualize the main dimensions identified by the data analysis. In this way, we can discover "recurrent phenomena in the flow of events..., and detect[] patterns among these recurrent relations" (Miles and Huberman, 1994, p. 276).

\section{Results: Causal diagram of usage factors for ESN, email, and other collaboration tools}

After presenting the main articulations between ESN, email and collaborations tools, we analyze chains of causal relations related to the uses of these tools.

\section{Various articulations between ESN, email and collaboration tools}

The causal diagram we use to summarize our findings identifies factors that we detected for the use of email versus ESN versus other specialized collaboration tools. Our qualitative study thus suggests that both ESN and emails continue to be used at work, to perform distinct tasks and address different organizational, individual, and collective needs. In particular, the empirical study indicates that organizations use email and ESN in parallel, not as direct alternatives. Although in practitioner studies and organizational planning, ESN initially were proposed as substitutes for email (i.e., reduce information overload and emails misuses as a corollary of broader objectives, such as restructuring access to information and communication flows), following their implementation, they largely were perceived as technologies that address different needs. Emails, despite their misuses and drawbacks, are still considered necessary, and accordingly, it seems difficult to include additional technologies on top of this major communication tool, especially if they seem redundant or confusing within the organizational context (Kalika et al., 2007). Rather than pure replacement, we find combinations and synergies between the tools, reflecting the employees' needs and uses.

We also find other, more specific collaborative tools in use, as alternatives to email or ESN. In most cases, these tools were not really organizationally prescribed but rather introduced 
and advertised by individuals or groups according to an underlying bricolage logic (Ciborra, 1997, 1999) or reverse adoption logic (Leclercq-Vandelannoitte, 2015). Our findings thus highlight that various relations and articulations exist in the uses of these tools, which we investigate further.

\section{Chains of causal relations}

Taking some distance from the field, we propose an explanatory construction of the reality we observe empirically, to identify the main themes and chains of causal relations. The findings suggest five main chains of causality (Chains A-E), as detailed in Figure 1:

- Chain A: Causes and consequences of employees' willingness to use tools other than email.

- Chain B: Causes and consequences of employees' need to access more useful information.

- Chain C: Causes and consequences of employees' need to improve the efficiency of their collaboration or coordination processes.

- Chain D: Causes of employees' actual use of specific collaboration tools (e.g., Slack, Trello).

- Chain E: Causes of employees' actual use of an ESN.

We also list the causal chains in Table 5.

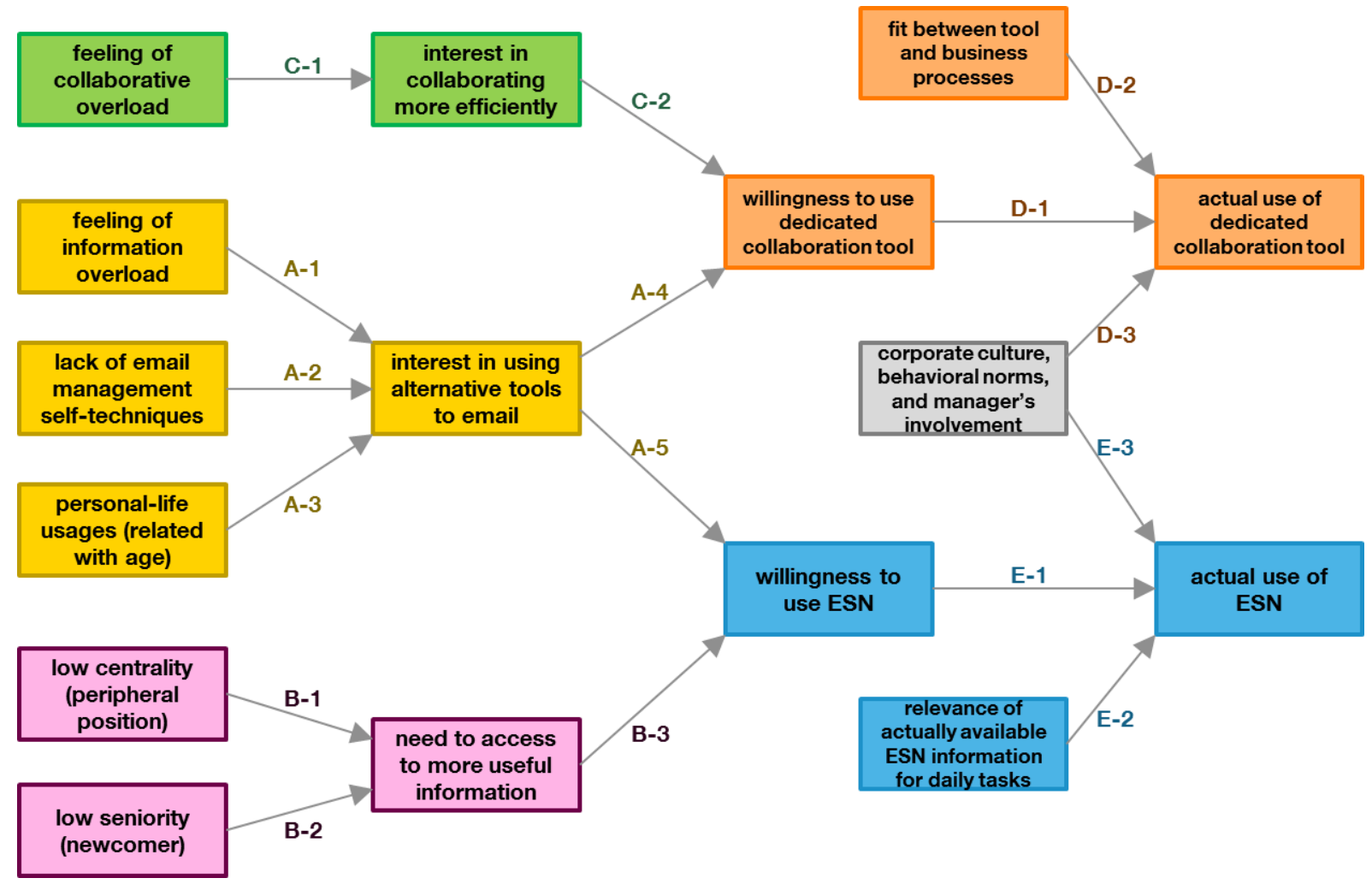

Figure 1: Causal diagram of the articulations of ESN, collaborative tools, and email

\begin{tabular}{|cc|}
\hline Proposal & Description \\
\hline A-1 & A feeling of information overload positively influences intentions to use alternative tools, \\
\hline
\end{tabular}




\begin{tabular}{|c|c|}
\hline & other than email. \\
\hline A-2 & $\begin{array}{l}\text { A lack of self-discipline to manage the email flow positively influences intentions to use } \\
\text { alternative tools, other than email. }\end{array}$ \\
\hline A-3 & $\begin{array}{l}\text { Personal uses of alternatives to email (e.g., Facebook, Snapchat, Instagram) positively } \\
\text { influence intentions to use alternative tools, other than email. }\end{array}$ \\
\hline A-4 & $\begin{array}{l}\text { The intention to use alternatives to email positively influences intentions to use a } \\
\text { dedicated collaboration tool. }\end{array}$ \\
\hline A-5 & The intention to use alternatives to email positively influences intentions to use an ESN. \\
\hline B-1 & $\begin{array}{l}\text { An employees' peripheral position (i.e., working hierarchically or geographically far from } \\
\text { decision centers) positively influences the perceived need to access more useful } \\
\text { information. }\end{array}$ \\
\hline B-2 & $\begin{array}{l}\text { A low seniority level (i.e., new employee) positively influences the perceived need to } \\
\text { access more useful information. }\end{array}$ \\
\hline B-3 & $\begin{array}{l}\text { The need to access more useful information positively influences the intention to use an } \\
\text { ESN. }\end{array}$ \\
\hline C-1 & $\begin{array}{l}\text { A feeling of collaborative overload (i.e., feeling of spending too much time to collaborate } \\
\text { or coordinate with colleagues) positively influences the perceived need to collaborate } \\
\text { more efficiently. }\end{array}$ \\
\hline $\mathrm{C}-2$ & $\begin{array}{l}\text { The perceived need to collaborate more efficiently positively influences intentions to use a } \\
\text { dedicated collaboration tool. }\end{array}$ \\
\hline D-1 & The intention to use a dedicated collaboration tool positively influences its actual use. \\
\hline D-2 & $\begin{array}{l}\text { Fit between a dedicated collaboration tool and users' business processes involving } \\
\text { collaboration positively influences its actual use. }\end{array}$ \\
\hline D-3 & $\begin{array}{l}\text { A corporate culture fostering collaboration and digital transformation, associated } \\
\text { behavioral norms, and the involvement and example of management positively influence } \\
\text { the actual use of alternatives to email (see E-3). }\end{array}$ \\
\hline E-1 & The intention to use an ESN positively influences its actual use. \\
\hline E-2 & $\begin{array}{l}\text { The relevance of information available on the ESN to help the employee fulfill daily tasks } \\
\text { positively influences its actual use. }\end{array}$ \\
\hline E-3 & $\begin{array}{l}\text { A corporate culture fostering collaboration and digital transformation, associated } \\
\text { behavioral norms, and the involvement and example of management positively influence } \\
\text { the actual use of alternatives to email (see D-3). }\end{array}$ \\
\hline
\end{tabular}

\section{Table 5: Causal Chains}

\section{Chain A: Interest in using alternative tools to email}

The first chain comprises factors that raise people's interest in using alternative tools, other than email. Our findings suggest classifying these factors into three main groups: information overload, lack of email management techniques, and personal uses.

All our interviews included some mention of information overload due to email use. Even people in junior positions, who receive relatively fewer emails, recognize that their colleagues are overwhelmed. For example, a management control director at PleinDénergie noted, "I receive sometimes 200 emails per day" [feeling of information overload]. The cited problem is not the volume of email itself but the volume of information they must review to perform their job, with the sense that "If I had less interesting emails, I would also have less to manage (laugh)" [feeling of information overload]. This finding aligns with examples from research and practice. For example, Atos conducted a survey in 2010 to monitor the quantity of email 
sent or received. The 300 surveyed employees sent or received more than 85,000 messages in a single week (Burkus, 2016) - an average of 60 messages per day [feeling of information overload]. Our participant observation confirms this situation. However, in our observations, the sense of information overload is more impactful than the objective measure of the number of received messages. For some respondents, 20 messages per day would represent a lowlevel flow, but others experience a feeling of information overload due to the same number. Interest in using alternatives to email thus appears correlated with a feeling of overload, rather than any simple objective measure.

More received emails does not necessarily lead people to reject email as a tool. Notably, the people at greatest risk of information overload have developed coping techniques, such that "Email overload is there, but it is not a difficulty for me. I manage it well, perhaps because of my experience" (marketing and CRM manager, PleinDénergie) [email management selftechniques]. Developing such techniques even appears to limit or prevent the use of ESN, such that many respondents justified their non-use of the internal ESN tool by citing their ability to find all the needed information quickly in their emailboxes [A-2]. A sales representative protests that by using the existing emailbox, "I know where is the information, so the search time is quite minimal" (BelleCulture). Some coping techniques are highly elaborated; an auditor from PleinDénergie details a complex process: "Each email I receive is immediately classified by topic; at the beginning, I needed some time to find good topics and good names for my folders, but it helps me gain plenty of time-I believe I have managed to adapt the tool to my needs" [email management self-techniques]. The techniques reflect the underlying messaging function of email, as well as its ability to classify and archive messages, often after a quick look. Such techniques cannot be replicated easily on an ESN tool, for which the information flow is not structured into messages [A-2].

However, a sense of information overload is not solely due to a lack of email management techniques. In some cases, this feeling of information overload arises despite the use of such techniques. For example, managers with broad responsibilities, such as those who supervise more than 70 people, sought tools to reduce their sense of overload for not only their own use but also to promote a cultural norm of sending fewer emails, which would benefit themselves as well as the whole unit $[A-1]$. Yet in the field observations, we identify a dearth of such techniques, such that their sense of information overload led people to ask for other tools (alternatives to emails). At Spinach Tech, software developers privilege such alternative tools; even if they do not suffer from an objectively high level of information overload, they still consider email a distraction from their primary work and privilege communication tools that are more closely integrated into their development environment and habits [A-1].

The third factor is the ease with which people use social networking tools in their personal lives, which appears partly correlated with age. "For me, the ESN has made life simpler —or at least the life of a younger person, because often young people are often on social media," according to a young engineer at PleinDénergie [A-3]. Older people use their age to explain why they do not use ESN, claiming "I am too old to use it" (system architect, Banque Bonjour) [A-3]. In a related explanation, they note that social networks are not part of the way they usually communicate: "For youngsters, social networks are part of their culture; for us, it is difficult to deal with" (plant manager, around 50 years of age, BelleCulture). Similarly at Spinach Tech, many participants reported that they were too old to change their working habits $[A-3]$. However, this factor is not universal, and some people in the same age interval (e.g., 40 to 50 years) describe how they changed their habits to embrace the use of ESN. The difference thus appears related more to how much they use social media tools in their private lives, which may correlate with age. As Facebook usage continues to spread in the general population, including older people, this aging factor may become less important [personal-life 
usages]. This finding emphasizes how private, mass market uses can inform uses of enterprise tools, in line with IT consumerization trends (Harris et al., 2012; Köffer et al., 2015a, 2015b).

Nor are ESN the only tool that digital natives use. Some younger informants describe Facebook and Twitter as mass market tools for older people, whereas they use Instagram or Snapchat in their private spheres, such that the features and user experience are quite different from those offered by current ESN. Even a "Facebook at work" initiative, commercially launched in 2016 by Facebook and renamed "Workplace," does not replicate Facebook features but rather adds new, specialized elements, like chatbots, that are not specifically linked to social networks. It recently moved to its own domain name (workplace.com), seemingly to gain distance from Facebook (CNBC, 2018).

These three factors all correlate positively with people's interest in using alternative tools, other than email $[A-1, A-2$, and $A-3]$, as depicted in our causal diagram. This interest in alternative tools also correlates with a willingness to use ESN [A-5] or dedicated collaboration tools $[A-4]$, reflecting the belief that "We can no more continue to increase email usage like this; we need to move to something else at one moment or another" (unit manager, Spinach Tech) [A-4 and A-5]. Our observations and interviews thus imply that the choice between ESN and dedicated collaboration tools depends on other factors.

\section{Chain B: Need to access more useful information}

Our data suggest that the main interest in using ESN results from employees' need to access more useful information than what is currently available. This need for useful information correlates with a peripheral position and low seniority [B-1 and B-2]. For example, low seniority triggers the use of ESN to find information, because "With my experience, I know more or less who are the experts in my field, but that is not the case for younger people" (CRM manager, Banque Bonjour) [B-2]. For more senior employees, using the ESN is less convenient than directly calling an expert, because "I spend more time to find information in the ESN than calling a colleague to get it. When you have spent some time in a company, you know who to call" (CRM manager, Banque Bonjour) [B-2]. But for junior employees, the ESN can at least partly replace the lack of human networks or relationship capital.

In this context, a peripheral position implies the person is not directly involved in decisions or power networks, such as employees who work for agencies rather than headquarters. Thus its meaning is not limited to a geographic sense but extends to any employees with less responsibility for the day-to-day business of the company (e.g., communications, R\&D units). Therefore, "To ease access to internal information while controlling its quality can really ease the work of operations people in agencies" (digital communication manager, Banque Bonjour) [low centrality], such that employees in peripheral positions want to find valuable information to address their day-to-day concerns, and some of them use ESN to do so [B-1]. Others use the ESN channel to advertise their own successes [B-3]. This finding emphasizes the benefits of a dual mode for ESN, with both descending and ascending hierarchical information flows. However, the social benefits of ESN (e.g., ability to establish social networks among contacts) were not mentioned often; they do not appear to drive the use of ESN.

Finally, our research indicates that ESN mainly serve to provide access to information rather than for other features, such as instant exchanges. In brief, "Email is more conventional, it is centered on the message, while ESN are centered on information" (digital communication manager, Banque Bonjour) $[B-3]$. The need to access more useful information than received 
from existing communication tools thus represents another driver of willingness to use ESN $[B-3]$, along with interest in using alternatives to email.

\section{Chain C: Need to collaborate more efficiently}

The third chain emerged occasionally in the exploratory case studies; we explored it in greater depth during our longitudinal observation at Spinach Tech, which featured a clear rise in what we refer to as "collaborative overload." This form of overload was primarily prominent among people whose jobs required them to coordinate others' efforts, such as for software development projects, because "With our new devops projects [i.e., methods blurring the frontiers between development and operations part of a software project], I have to coordinate not only with software developers, but also with people from operations and even from sales" (technical architect, Spinach Tech) [feeling of collaborative overload]. Coordination demands seem strengthened by new methodologies like devops or agile development, such that "Before agile methods, I used to first coordinate with my business unit on the roadmap, and then organize the planning of my developers accordingly.... Now with agility, I have to ensure a kind of real-time coordination between the business owner who invests, the product owner who specifies the roadmap, the developers who make the code, and the validator who tests its features. What a nightmare! (laughs)" (project manager, Spinach Tech) [C-1].

These difficulties also pushed people to consider using dedicated collaboration tools, because their collaboration and coordination needs were not being fulfilled by the existing Spinach Tech ESN (called Places): "I tried to use Places to synchronize within my team, but the tool is clearly not made for that!" (product manager, Spinach Tech) [C-2] and "Places is good for broadcasting information $[B-3]$ and eventually to get some feedback, but it's not designed for everyday collaboration $[C-2]$ " (developer, Spinach Tech). Similarly, they noted limitations of email, in which context their sense of collaborative overload increased their perception of information overload: "I didn't see how I could sort out my mailbox, between emails related to my project and other stuffs, so I tried to move everything concerning the day-to-day life of my project to another tool" (technical architect, Spinach Tech) [C-2].

Our observations indicate that the employees mainly turned to tools oriented toward conversations, similar to the Internet relay chat function from the early web. For example, a commercial product called Slack was an early entrant; its name is an acronym for "Searchable Log of All Conversation and Knowledge," which describes its purpose. Another option called Spark was built by Cisco with the same purpose. Open-source alternatives exist too, such as Mattermost. These tools all are structured around channels: A user subscribes to a channel and then is notified of any activity. They thus adopt a "publish-subscribe" pattern, in contrast with email that uses a "send-receive" pattern (Alimam et al., 2015). Activity could be a message, but it also could be shared information from another tool, such as question raised in a collaborative specification editing tool, the deployment of running code, or even customer relationship management elements. Slack advertises its ability to link to hundreds of thirdparty applications that function as a kind of federator among various business applications. All the activity on a channel is searchable by all its subscribers, so it constitutes a basic, easyto-use knowledge base. Whereas email users have only one mailbox, the users of these tools can follow various channels, each specific to a topic or project [C-2]. These usages accordingly cannot substitute for email, which remains necessary for general communications. Rather, the specific tools support collaborations within groups that have specific goals (e.g., cross-functional project teams) (Tran and Bertin, 2015). 


\section{Chain D: Actual use of dedicated collaboration tool}

A perception of collaborative overload by itself [D-1] is not enough to prompt uses of alternative tools. We thus identify two other factors: the integration of the new collaborative tool with day-to-day business processes $[D-2]$ and the corporate culture $[D-3]$. In particular, most of our informants mentioned integration with other business tools as decisive to their adoption of dedicated collaboration tools (Bertin and Crespi, 2009). Tools like Slack or Mattermost include many plugins to connect with other IT tools, such that "My Mattermost is connected to Github so when a developer publishes a new version of his or her code, I am immediately notified through a dedicated Mattermost chat channel" (project manager, Spinach Tech) [D-2]. Moreover, early adopters build their own connectors. A lead architect from Spinach Tech developed a connection between a collaborative tool that can design and edit specifications (e.g., of API to be coded by developers) and the Mattermost chat tool. As soon as a new version of the specification or questions about an existing API appear, the user receives notification through Mattermost and then can answer in the dedicated chat channel [D-2]. As a persistent channel, it progressively builds a knowledge base dedicated to the focal topic (e.g., a specific API), which other project members can consult as needed. Therefore, "All the people involved in the project are now connected through this tool, even business owners and operational support teams... We have nearly managed to eliminate emails inside my project .... and that's pretty cool for day-to-day work efficiency!" (project manager, Spinach Tech) $[D-1]$.

A corporate culture that features the freedom to experiment and make choices also encourages the use of alternative tools, some of which the participants build themselves [D-3]. These early adopters then can promote their tools to their teams (project or hierarchical) and incrementally spread them across the company. Managers are less influential in this case, because the use of these tools appears driven by the employees, first through a bricolage process (Ciborra, 1997, 1999), such that employees seek to build their own tools, and then through a reverse adoption process (Leclercq-Vandelannoitte, 2015), such that the new usages spread throughout the organization [D-3]. This model raises governance issues, yet such usages also can create a space for experimenting with a new liberal model of IT governance that recognizes employees' ability to introduce or develop their own tools, as well as take on the associated accountability (Leclercq-Vandelannoitte and Bertin, 2018).

The use of collaborative tools appears more common at BelleCulture and PleinDénergie, but less so at Banque Bonjour. The importance that this company assigns to compliance with strictly defined processes likely reflects the corporate culture required in the banking sector $[D-3]$.

\section{Chain E: Actual use of ESN}

Willingness to use ESN [E-1] is only one of the factors that lead to their actual use. We also identify two other factors in our interviews: the relevance of information available through the ESN [E-2] and the corporate culture [E-3]. Although we again cite the corporate culture, the influence is different from that we described for Chain D. Here, it pertains to behavioral norms and managers' effective involvement (setting examples). Managerial attitudes toward collaboration and transparency inform the corporate culture, but so do behavioral norms implicitly internalized by employees, even without any explicit managerial direction [E-3]. This conceptualization of corporate culture was frequently mentioned, mainly as a hindrance to ESN usage and especially among younger employees, such as the one who complained, "Enterprise culture plays a role, in particular in questions of transparency, because our ESN is a tool that implies transparency and that can only work in this kind of environment" (project 
manager, about 20 years of age, BelleCulture) [E-3]. Another determinant of the corporate culture is the sector in which the company operates: "Concerning corporate culture for creating and sharing information - it's difficult, as we are in the banking sector ... to a certain extent, this prevents any conservation or sharing of information in a spontaneous manner" (branch manager, Banque Bonjour) [E-3].

A key obstacle to the diffusion and adoption of ESN also arises from anticipated negative impacts on interpersonal relations, which rely on existing behavioral norms [E-3]. For example, the Banque Bonjour interviewees often rejected ESN to avoid the risk of making human relations more distant, an effect that could spread to their private lives. They express their continued attachment to face-to-face, concrete conversations over virtual relationships. The problem of interpersonal relations also pertains to fear for their image; several interviewees admitted that because everything posted on the ESN is public, they were afraid of receiving negative feedback, such as a CRM manager at Banque Bonjour who stated, "Imagine if my question or comment is misunderstood. My reputation could suffer from that!" [E-3] Users try to keep their claims or comments as "corporate" as possible, which biases their participation.

In addition, some interviewees call for managers to provide an example. They cannot simply encourage the use of the tool but also must use it themselves, in accordance with a more transparent attitude toward information. Warns an auditor at PleinDénergie, "If you want such a tool (ESN) to be used and deployed, managers should assimilate it; it will not work without managerial appropriation." [E-3] The introduction of ESN disrupts power distributions, by making information more transparent than it is with the use of email. Because "The one who has the information has the power, it's difficult to share information, and this is not a matter of generations" (business development manager, BelleCulture). Email has provided a good vehicle for maintaining power-knowledge relationships, in a Foucauldian sense (Foucault, 1977), because it enables tight control over which information is received and disclosed. The more power an organizational actor exerts, the more emails that person receives and send. In turn, email overload may be linked not to the tool but rather to the power structure of the enterprise. From this perspective, ESN challenges existing power structures with new usage patterns, marked by information transparency and horizontality (i.e., anyone can contribute in the same way), which may explain its limited adoption and use among managers [E-3].

The use of ESN thus might push corporate culture to evolve, favoring the emergence of ideas and innovation. Even though ESN are reserved for internal communication among familiar colleagues, they can open access to novel ideas, expertise, or best practices; such access is one of the main identified benefits of ESN implementation (McAfee, 2009). Because they centralize access to different platforms, create one unique homepage, and halt the proliferation of different intranets and platforms, ESN help standardize the different collaborative tools available to members of the company. In turn, they must use a single tool, instead of turning to multiple platforms. This mandate can create unity and a common corporate spirit that reflects the company culture, and it establishes a good channel for sharing across functions and services. Furthermore, ESN might evoke a more modern image of the company, which may reinforce employees' sense of belonging to the firm - a point widely mentioned by middle-aged employees. Finally, ESN create connections among different business entities and countries. By reinforcing unity, the company can foster sharing of best practices, ideas, and innovation. Most of the interviewees thus acknowledge the benefits of ESN for communication and knowledge or skill sharing. Such knowledge sharing also can be a way to attract new talent, who prefer to work with such collaborative tools.

Another factor [E-2] is the usefulness of information available on the ESN, cited as either a positive factor if information is available or a negative one otherwise. As a concrete example, 
the human resource ESN at PleinDénergie is perceived as useful and thus attracts substantial traffic; notably, it "is really widely used, because there are all the links for vacations, balances and so on; so when people need it, they use it!" (ESN project manager, PleinDénergie) [E-2]. However, if ESN do not meet the needs of users, they will not use it and instead might complain, "We face so much pressure and business-related issues, so we cannot spend hours on a tool that is useless for us" (product manager, BelleCulture) [E-2]. Our observations indicate that many users do not perceive any added value of an ESN, "because we can do our job without Yammer. It does not add much value to our work" and instead is "another distraction from the business" (user, BelleCulture) [E-2].

We find similar attitudes at Spinach Tech, which instituted its ESN Places in 2011. As of May 2017, it featured approximately 110,000 users, about 50,000 of whom were active users who viewed 80,000 pages per day. In parallel, members of this company received an average of 2 million emails daily. The number of emails continued to rise, even after the introduction of the ESN, though the rate of increase had slowed. Despite the widespread use of the ESN tool, employees still need email for other types of information. In addition, we determine that ESN traffic appears mainly driven by communities. People rarely use the ESN without a specific purpose; they visit specific communities, to post or retrieve information. The communities usually consist of one key contributor and several people seeking specific information [E-2].

Accordingly, employees at PleinDénergie and BelleCulture identify the value of ESN as based on its "grouping function": It supports the development of communities that share professional interests, so workers can follow the news, participate in the group, or exchange details about a particular job or project. These groups are valuable for international firms too, because they allow users to work on shared themes across boundaries and distances. Another benefit of ESN stems from its storage function; at Banque Bonjour, the Inca platform lets workers access corporate information. PleinDénergie's ESN also collects and distributes corporate information. Our interviews confirm that knowledge management is a main function of ESN (Poinsot et al., 2010; Turban et al., 2011) [E-2]. Workers use it to file documents, save information, and retrieve them later. As a platform for information sharing and exchange, ESN also promote knowledge sharing from the most experienced workers to the least or from workers from a subsidiary to those at headquarters.

However, ESN cannot fulfill all business needs. As indicated in Chains C and D, we observe the rise of alternative tools, dedicated to a single collaboration usage. The findings related to actual uses of ESN, as summarized in Table 6, highlight some distinctive advantages relative to other communication tools (including email).

\begin{tabular}{|l|l|}
\hline \multicolumn{1}{|c|}{ Perceived Advantages of ESN } & \multicolumn{1}{c|}{ Perceived Limits of ESN } \\
\hline $\begin{array}{l}\text { Greater access to useful shared information } \\
\text { inside teams (E-2) }\end{array}$ & $\begin{array}{l}\text { Possible waste of time, lack of directly useful } \\
\text { information (E-2) }\end{array}$ \\
\hline $\begin{array}{l}\text { Create new trans-organizational informal } \\
\text { connections and foster cohesion (E-3) }\end{array}$ & $\begin{array}{l}\text { New behavioral norms still to be constructed } \\
\text { (E-3) }\end{array}$ \\
\hline $\begin{array}{l}\text { Facilitate access to information in a single } \\
\text { tool, especially for newcomers (E-1) }\end{array}$ & $\begin{array}{l}\text { Lack of global engagement on ESN from } \\
\text { those who developed techniques to master } \\
\text { other tools (including email), especially from } \\
\text { middle and senior managers (E-1) }\end{array}$ \\
\hline
\end{tabular}

Table 6: Main Perceived Advantages and Limitations of ESN 


\section{Discussion: ESN as a substitute for email?}

The resulting causal framework of the articulations of usage factors of email, ESN, and specialized collaborative tools contains three main implications. First, we enhance understanding of information overload by clarifying that it is not intrinsic to email and by analyzing the emerging notion of "collaborative overload." Second, we determine that ESN may not be the solution for fostering new behaviors. Third, workplaces do not need ESN tooling but rather require a digital transformation strategy, with more emphasis on meeting employees' needs instead of focusing solely on an ESN's promise for altering workplace culture and practices.

\section{Information overload is not a problem intrinsic to email}

This empirical study confirms that information overload is an issue, linked to the use of email (Ayyagari et al., 2011; Sobotta and Hummel, 2015). However, our study also clarifies that email is a vehicle of this overload, not its root cause. Employees do not incriminate email; instead, email misuses that reflect shared behavioral norms and power issues in organizations translate into specific practices that lead to information overload (e.g., excessive use of cc tools, lack of rigor in choice of recipients, emails sent at night, growing expectations of responsiveness). Furthermore, information overload relates to the employees' centrality within the organization and their place in the enterprise's organization chart-that is, in the power structure of the company (Foucault, 1977). The employees most exposed to information overload generally have developed self-discipline techniques (Foucault, 1988), enabling them to cope and manage continuous information flows within their email boxes. Such practices have emerged as an important (and perhaps differentiating) competency within work ecosystems, enabling their adherents to obtain adequate information to seize opportunities and make optimal decisions.

In addition to information or email overload, collaborative overload is widely perceived as a growing organizational issue (Cross et al., 2016). Collaborative overload results from pressures to conform to what employees regard as a strong organizational expectation and new behavioral norm, that is, the imperative to collaborate, as is frequently signaled by discourses and practices surrounding the digital transformation of companies. Our results highlight that organizations often deploy ESN for a specific reason: to foster an innovative, collaborative workplace culture, which valorizes collaboration as a means to circumvent organizational complexity, as well as to attract young talent. Such rationales may have little in common with employees' day-to-day business and coordination needs though.

This injunction to collaborate could lead to a culture of "collaboration for collaboration's sake" (Mankins, 2017). Despite global trends toward more collaborative practices, this outcome has not been studied extensively, especially in MIS (Barricelli et al., 2015; Cross et al., 2018; Mankins, 2017). Some employees spend a majority of their working time in collaborative activities (Cross et al., 2016), and collaboration duties are not equally split, such that an estimated $20 \%-35 \%$ of value-added collaborations involve only $3 \%-5 \%$ of employees - those with a more collaborative mindset and distinctive resources (e.g., knowledge, network position, time, energy). This scenario seems likely to evoke a feeling of both collaborative and information overload, especially among the overburdened employees.

Our empirical study emphasizes that issues of information and collaborative overload are interrelated, as well as linked to the likely evolution of working practices (toward collaboration and the constitution of employee communities), which organizations also increasingly embed in prescribed technologies (i.e., ESN). However, we show that innovative tools introduced by employees themselves are perceived as more useful and suitable for daily 
tasks than ESN prescribed by companies, reflecting a reverse adoption logic (LeclercqVandelannoitte, 2015).

Information overload cannot be solved simply by implementing new technologies, such as ESN, which cannot meet the coordination needs of employees but instead add to the problem by imposing another type of (collaborative) overload. Resolving the issue probably requires a deeper change to the way people interact at work. Alternatively, perhaps we should acknowledge that information overload is a constitutive element of modern work, in contexts marked by increased competitive pressures, faster times to market, complex work ecosystems, stringent coordination needs, and growing accountability at the individual level. The most pressing need thus might be to help employees cope, through the implementation of more dedicated collaboration tools that can address their specific needs.

\section{ESN is not a "killer tool"}

Whether as a tool to reduce information overload or help employees cope, ESN are not the "killer tool" that can transform how people interact. Instead, they offer an alternative option that could provoke another type of overload, even as organizations legitimize them as ways to facilitate coordination and collaboration within and between teams. Our findings affirm some primary advantages of ESN: transparency and a distinctive ability to create open communities for sharing and interacting with information, which is particularly beneficial for newcomers and peripheral employees. These employees struggle with information access through email, because they generally are not included in the main information flows. In that sense, ESN achieve some of the promises of document management systems, in that they help employees search for and access internal resources and documents.

However, misuses (e.g., threats to users' reputation, managers' examples) are also evident to organizational actors, and the behavioral norms for these tools have yet to be established. Behavioral norms are key to sustainable usage though. Social networks have spread widely in personal arenas, and ESN promoters anticipated that this massive mass market usage would create a solid foundation for building ESN usage norms within companies. But as our empirical study reveals, the enterprise context is different from private ones, and these differences hinder any simple transfer of mass market practices to companies-especially when a majority of employees do not recognize any perceived utility or ease of use of ESN (Venkatesh and Davis, 2000). Beyond the choice to deploy ESN, organizations must foster new behaviors through real organizational and cultural transformations within companies.

\section{The key is not ESN tooling but a digital transformation strategy}

As suggested by our literature review and confirmed by our interviews, ESN are often presented and legitimized by organizations as a way to change the organization's culture and encourage more collaborative practices. However, and paradoxically, our empirical study reveals that ESN are not the best tools to transform work practices; at best, they represent new tools that offer some interesting functions, especially for information sharing. But the results emphasize a key prerequisite, in that employees must perceive clear, immediate added value before they will use the implemented tool for their own work. In turn, we argue that new tools such as ESN should not be presented as a way to change enterprise culture, as is common during ESN deployments, but rather as an opportunity to add work value (i.e., helping employees complete their daily tasks more easily). Such an approach also might benefit from privileged deployments by local business units or IT, instead of human resource, departments.

Our study also highlights the need to locate ESN implementation within a broader digital transformation strategy with clear objectives, rather than focusing just on the expected promises of the specific tool for the company's culture and practices. Instead of deploying a 
single ESN tool, our results promote the introduction of multiple, dedicated collaboration tools that address different, clearly defined work needs, including ESN. Practitioners should consider more specialized tools, in addition to ESN (e.g., Etherpad or Google docs for collaborative editing, Github for code or documentation repository and versioning, Slack or Mattermost for teamwork). The use of such technologies has expanded, because they facilitate the combination of personal, team-wide, and community-wide objectives, while also directly supporting employees' daily tasks and business processes. In deploying such specific tools, companies might enable their technically savvy employees to set them up, in coordination with IT departments (Leclercq-Vandelannoitte and Bertin, 2018; Tran and Bertin, 2015). Companies willing to implement such an IT strategy should pay particular attention to integrating the various tools, perhaps using task automation tools such as IFTTT or Zapier. Finally, by communicating the "big picture" to users, companies can clarify how the combinations of these tools will help them, which should foster their adoption.

\section{Conclusion}

To conclude, we first analyze the conceptual implications, limitations and avenues for further research of this study, before presenting some practical recommendations.

\section{Implications, limitations, and avenues for further research}

This study adds an organizational perspective to academic research into email and ESN by studying the articulations between these two technologies. We confirm the strength of IT usage habits (Pillet and Carillo, 2016) and the relevance of millefeuille theory and its prediction of a superposition effect of communication tools rather than their replacement. As Kalika et al. (2007) observe, substitution between electronic and face-to-face communications is rare (less than $15 \%$ of cases). Similarly, the cases we study indicate that emails and ESN superimpose on each other, rather than substituting. In that regard, we propose moving beyond well-established MIS theories of adoption (Davis, 1989; Venkatesh and Davis, 2000; Venkatesh et al. 2003) to develop more contextual analyses of articulation processes for various IT uses in corporate settings (with possible substitution and interaction effects), in contexts in which technologies increasingly superimpose on each other and extend beyond organizational boundaries (Crowston et al., 2010).

Most extant theories focus on implementation, rather than how the context influences the success of the articulation process or factors that encourage or inhibit substitutions of one tool by another. To address articulation and potential replacement questions, we take a different perspective that acknowledges the importance of power relations and the context. In particular, we show that ignoring the implementation context and articulation can adversely affect the appropriation of an ESN (or similar technologies) and its interactions with other tools. This research thus suggests an explanation for why some companies have reported failures in their attempts to implement ESN and reduce internal emails (and the associated information overload problem)-namely, due to the challenges of getting employees and managers to adopt such tools by changing their working habits and beliefs about the implications of information sharing. We also advance understanding of the emerging concept of collaborative overload (Cross et al., 2018), which emerges as a corollary of information overload but that has received less attention in MIS research. In addition, this research confirms the relevance of adaptive use intention theory (Chandra et al., 2011; Shirish et al., 2016), which seems particularly appropriate to understand the factors that lead to the adoption or non-adoption of ESN, especially among young employees in corporate settings. 
Some limitations also suggest potential paths for research. Our exploratory study, coupled with our longitudinal observation of a telecommunications company, enabled us to achieve a kind of saturation in our coding process, leading to the proposed causal diagram. However, different effects and articulations might arise in other contexts or with different kinds of organizations and technologies. Additional research could apply our findings to the articulation of ESN and email in other contexts and, more broadly speaking, to the articulation of other technologies at work. Nor do we analyze the non-organizational uses of technologies, which might extend the organizational realm (Crowston et al., 2010), so we call for additional research in that direction. We exclude any role of national culture in our study, in that our data all come from French firms. This dimension might influence the articulation process of various technologies at work though, so researchers should check for cultural differences in the articulation process of various technologies. Ultimately, the proposals we derive from our causal diagram require further validation by quantitative studies, to assign more empirical strength to our findings.

\section{Practical recommendations}

Despite its limitations, this research should have some practical interest for managers and executives who seek to develop unified communications through a convergent set of technologies that promise to help people communicate more effectively. We show that ESN can foster collaboration, transparency, and information sharing, but we also explain recent failures of such tools, due to misunderstanding of their articulations with existing technologies such as email. With this insight, we can suggest two main populations to target for successful ESN deployment. First, companies should engage middle and senior managers, perhaps by setting specific goals for their ESN usage (e.g., quantity of posts or shared documents). This group simultaneously exerts the most influence on the company's culture and has the most useful information to share, but it also tends to be more reluctant to share the information it has. Therefore, managers need to be more closely involved in the use of ESN at work. Second, companies should target peripheral employees (e.g., newcomers, those hierarchically or geographically far from decisions centers), who need greater access to information, because they are poorly connected to the main information flows. They are thus natural early adopters of ESN. Combining these two targets would expand content, willingness to share information (from middle and senior management and experts), and reach/activity (from peripheral employees). This combination could create the critical mass to ignite ESN success, by building a sufficiently strong value proposal (Metcalfe, 2013).

Even as we recommend such specific targeting and criteria, implementation processes must be designed carefully in accordance with a broader digital transformation strategy that details uses of other technologies too. Such a strategy should account for employees' expectations, job tasks, and coordination needs; it must move beyond a discursively constructed promise to change the workplace culture with ESN. Rather than replacing email with ESN, employees demand more synergies between technologies. According to our results, email is neither the walking dead nor the lone survivor (Colléaux et al., 2017). It continues to represent an important component within the evolving communication portfolio, in which no single product can account for all uses. Rather, different tools must cohabitate within this portfolio to be able to fulfill the various and growing requirements of enterprise-level collaboration.

\section{References}

Adam, R. (2002), “Is e-mail addictive?”, Aslib proceedings, 54(2), p. 85-94. 
Addas S. and Pinsonneault A. (2015), "The Many Faces of IT Interruptions: A Taxonomy and Preliminary Investigation of their Performance Effects”, Information Systems Journal, 25(3), p. 231-273.

Addas, S. and Pinsonneault, A. (2018), "E-Mail Interruptions and Individual Performance: Is There a Silver Lining?", MIS Quarterly, 42(2), p.381-405.

Alimam, M., Bertin, E. and Crespi, N. (2015), "Enterprise Social Systems: The What, the Why, and the How," IEEE 17th Conference on Business Informatics, Lisbon, p. 9-17.

Altimeter Group (2012), "Making the Business Case for Enterprise Social Networks", Altimeter Group, San Mateo, CA.

Anderson, S. and Mohan, K. (2011), "Social Networking in Knowledge Management", IT Professional, 13(4), p. 24-28.

Avram, G. (2006), "At the crossroads of knowledge management and social software", Electronic Journal of Knowledge Management, 4(1), p. 1-10.

Ayyagari, R., Grover, V. and Purvis, R. (2011), "Technostress: technological antecedents and implications", MIS Quarterly, 35(4), p. 831-858.

Barley, S. R., Meyerson, D. E. and Grodal, S. (2011), "E-mail as a Source and Symbol of Stress", Organization Science, 22(4), p. 887-906.

Barricelli B.R., Fischer G., Mørch A., Piccinno A. and Valtolina S. (2015), "Cultures of Participation in the Digital Age: Coping with Information, Participation, and Collaboration Overload" in End-User Development, Díaz P., Pipek V., Ardito C., Jensen C., Aedo I., Boden A. (eds), IS-EUD 2015. Lecture Notes in Computer Science, vol 9083, Springer, Cham.

Becker, P. (2013), "Knowledge-Sharing Platform to Support Zero-Mail Policy: The Classroom as a Case Study" in Beyond the Cloud: Information...Innovation...Collaboration..., Y. Tonta et al. (eds), 4th International Symposium on Information Management in a Changing World. Limerick, Ireland: Hacettepe University Department of Information Management, p. 63-65.

Bellotti, V., Ducheneaut, M. Howard, I. Smith, and Grinter, R.E. (2005), "Quality versus quantity: E-mail-centric task management and its relation with overload", Human-Computer Interaction, 20(1), p. 89-138.

Benbasat, I., Goldstein, D. K., and Mead, M. (1987), "The case research strategy in studies of information systems”, MIS Quarterly, 11(3), p. 369-386.

Bertin, E. and Crespi, N. (2009), "Service business processes for the next generation of services: a required step to achieve service convergence", Annals of telecommunications, 64(3-4), p. 187-196.

Boukef, N. and Kalika, M. (2002), "Les facteurs déterminants de l'utilisation du courrier électronique" in e-GRH: révolution ou évolution, Kalika, M. (ed), Liaisons, p. 145-169.

Boukef, N., Charki, M., and Kane, G. (2017), "When Online Ties are not Enough in Enterprise Social Media Networks", Academy of Management Annual (AoM) Meeting

Boukef, N,A. Mlaiki, and Walsh, I. (2017), "Why do we continue using social networking sites? The giving loop that feeds computer-mediated social ties", Systèmes d'information \& management, 22(2), p. 5-47.

Boyd, D. M. and Ellison, N. B. (2007), "Social network sites: Definition, history, and scholarship", Journal of Computer Mediated Communication, 13(1), p. 210-230. 
Burkhardt, M. E. and Brass, D. J. (1990), "Changing patterns or patterns of change: The effects of a change in technology on social network structure and power", Administrative Science Quarterly, 35(1), p. 104-127.

Burkus, D. (2016), "Some Companies Are Banning Email and Getting More Done". https://hbr.org/2016/06/some-companies-are-banning-email-and-getting-more-done

Burton, P., Wu, Y. and Prybutok, V. R. (2010), "Social network position and its relationship to performance of IT professionals", Informing Science: The International Journal of an Emerging Transdiscipline, 13(1), p. 121-137.

Butcher, H. (1998), “Meeting managers' information needs", ASLIB.

Byron, K. (2008), "Carrying too heavy a load? The communication and miscommunication of emotion by email”, Academy of Management Review, 33(2), p. 309-327.

Capra, R., Khanova, J. and Ramdeen, S. (2013), "Work and Personal E-mail Use by University Employees: PIM Practices Across Domain Boundaries", Journal of the American Society for Information Science and Technology, 64(5), p. 1029-1044.

Chandra, S., Srivastava, S.C., and Theng, Y.L. (2012), "Cognitive Absorption and Trust for Workplace Collaboration in Virtual Worlds: An Information Processing Decision Making Perspective", Journal of the Association for Information Systems 13(10), p. 797-835.

Ciborra, C. (1997), "De Profundis ? Deconstructing the Concept of Strategic Alignment", Scandinavian Journal of Information Systems, 9(1), p. 67-82.

Ciborra C. (1999), “A Theory of Information Systems Based on Improvisation” in Rethinking Management Information Systems, Currie WL. et Galliers B. (eds), Oxford university press, Oxford, p. 136-155.

CNBC (2018), "Facebook is separating Workplace from the main Facebook site to appease business customers concerned about security", CNBC report, Oct. 30, 2018 https://www.cnbc.com/2018/10/31/facebook-introduces-workplace-domain-to-calmenterprise-security-fears.html

Colléaux A., Bertin E., and Leclercq-Vandelannoitte A., (2017), "Email: survivor or walking dead? An exploratory study of the potential replacement of email by enterprise social networks", Colloque AIM (Association Information Management), Paris, France.

Conley, C. A. (2013), "Identifying critical success factors for Enterprise Social Network success" in Collaborative Knowledge Networks, H. Roche (ed.), Ark Group, Peoria, p. 29-34.

Cross, R., Parker, A., Prusak, L. and Borgatti, S. P. (2001), "Knowing what we know: Supporting knowledge creation and sharing in social networks", Organizational dynamics, 30(2), p. 100-120.

Cross, R., Rebele, R., and Grant, A. (2016), "Collaborative Overload", Harvard Business Review, January-February, Issue, p.74-79.

Cross, R., Taylor, S., and Zehner, D. (2018), "Collaboration Without Burnout", Harvard Business Review, July-August, Issue, p. 134-137.

Crowston, K., Fitzgerald, B., Gloor, P., Schultze, U. and Yoo, Y. (2010), "Shifting boundaries: how should IS researchers study non-organizational uses of ICT?", ICIS 2010 Proceeding, Paper No. 119, St Louis, MO, available at: http://aisel.aisnet.org/icis2010_submissions/119. 
Cudicio, R. and Proulx, S. (2006), "La messagerie instantanée en entreprise: Accélérateur ou frein à la productivité?”, Colloque semaine de la connaissance.

D'Anselme, F. (2014), "Atos Zero Email: Enterprise cultural change beyond Social Collaboration", Retrieved 19.07.2019, from https://atos.net/en/blog/atos-zero-emailenterprise-cultural-change-beyond-social-collaboration

Dabbish, L. A. and Kraut, R. E. (2006), "Email overload at work: An analysis of factors associated with email strain", Proceedings of the 20th anniversary conference on Computer supported cooperative work. Alberta: ACM, p. 431-440.

Dabbish, L. A., Kraut, R. E., Fussell, S. and Kiesler, S. (2005), "Understanding email use: predicting action on a message", Proceedings of the SIGCHI conference on Human factors in computing systems. ACM, p. 691-700.

Dabbish, L., Stuart, C., Tsay, J. and Herbsleb, J. (2012), "Social coding in GitHub: transparency and collaboration in an open software repository", CSCW'12 Proc. of the ACM Conf. on Computer Supported Cooperative Work, ACM, 1277-1286.

Daft, R.L.. and Lengel, R.H. (1986). "Organizational information requirements, media richness and structural design”, Management Science, 32 (5), p. 554-571.

Datchary, C. (2005), "Se disperser avec les TIC, une nouvelle compétence?" in Travailler aujourd'hui avec les technologies de l'information, E. Kessous and J. Metzger (eds), Hermès, Paris, p. 157-173.

Davis, F. D. (1989). "Perceived Usefulness, Perceived Ease of Use, and User Acceptance of Information Technology," MIS Quarterly, 13(3), p. 319-339

Dawley, D. D. and Anthony, W. P. (2003), "User perceptions of e-mail at work", Journal of Business and Technical Communication, 17(2), p. 170-200.

Denis, J. and Assadi, H. (2005), "Les usages de l'e-mail en entreprise, efficacité dans le travail ou surcharge informationnelle?" in Le travail avec les technologies de l'information, E. Kessous and J. Metzger (eds.) Hermes, Paris, p. 135-155.

Derks, D. and Bakker, A. B. (2010), "The Impact of E-mail Communication on Organizational Life", Cyberpsychology: Journal of Psychosocial Research on Cyberspace, 4(1), article 4.

DiMicco, J. M. et al. (2009), "People Sensemaking and Relationship Building on an Enterprise Social Network Site", HICSS'09, 42nd Hawaii International Conference on System SciencesIEEE, p. 1-10.

Ducheneaut, N. and Bellotti, V. (2001), "E-mail as habitat: an exploration of embedded personal information management", Interactions, 8(5), p. 30-38.

Ducheneaut, N. and Belotti, V. (2003), "Ceci n'est pas un Objet? Talking About Objects in Email”, Human-Computer Interaction, 18(1), p. 85-110.

Ducheneaut, N. and Watts, L. A. (2005), "In search of coherence: A review of e-mail research", Human-Computer Interaction, 20(1-2), p. 11-48.

Edmunds, A. and Morris, A. (2000), "The problem of information overload in business organisations: a review of the literature", International journal of information management, 20(1), p. 17-28.

Ellis C., Adams T. and Bochner, A. (2011), “Autoethnography: An overview”, Historical Social Research, 36(4), p. 273-290. 
Ellison N.B., J.L. Gibbs, and Weber, M.S.(2015), "The Use of Enterprise Social Network Sites for Knowledge Sharing in Distributed Organizations", American Behavioral Scientist 59(1), p. 103-123.

Fidelman, M. (2013), "The Rise of Enterprise Social Networks"? https://news.microsoft.com/download/presskits/enterprisesocial/docs/riseEnterpriseSocial WP.pdf

Figueroa, J. and Cranefield, J. (2012), "Creating and sharing knowledge through a corporate social networking site: the impact of employees' perceptions on effectiveness", PACIS 2012 Proceedings. AIS.

Filippone, D. (2014), “Zéro mail chez Atos : la SSII a-t-elle gagné son pari ?”, JDN [online], March 15, Available at: http://www.journaldunet.com/solutions/reseau-social-dentreprise/atos-strategie-zero-mail.shtml [Accessed July 19, 2019].

Forsyth, D. K. and Jenkins, L. R. (2009), "Strategies to reduce Email Overload", 2009 International Conference on COmputer Engineering and Applications. Singapore: LACSIT Press, p. 106-112.

Foucault, M. (1977), "Discipline and Punish: The Birth of the Prison", Allen and Lane, London.

Foucault, M. (1988). "Technologies of the Self: A Seminar with Michel Foucault", Tavistock, London.

Fraser, M. and Dutta, S. (2010). "Throwing sheep in the boardroom: How online social networking will transform your life, work and world", John Wiley and Sons, London.

Frazee, V. (1996), "Is e-mail doing more harm than good”, Personnel Journal, Volume 23.

Fredd, M., Carbonell, J. G., and Gordon, G. J. (2008), "RADAR: A Personal Assistant that Learns to Reduce Email Overload”, AAAI., p. 1287-1293.

Gallup (2013), "State of the American Workplace: Employee Engagement Insights for U.S. Business Leaders", Gallup Research.

Girin J. (1981), "Quel paradigme pour la recherche en gestion ?", in Économies et Sociétés, Tome XII, n¹0-11-12, octobre-novembre, p. 1871-1889.

Glaser, B.G and Strauss, A.L., (1967), "The Discovery of Grounded Theory: Strategies for Qualitative Research", Aldine Publishing Company, Chicago.

Glei, J. (2016), "Five years of your life on email? Time to try some inbox management", The Guardian. $\quad$ https://www.theguardian.com/commentisfree/2016/nov/14/email-inboxmanagement-happy

Gofine, M. and Clark, S. (2017), "Integration of Slack, a cloud-based team collaboration application, into research coordination", Journal of Innovation in Health Informatics, 24(2), p.251-253.

González, V. M. and Mark, G. (2004), “Constant, constant, multi-tasking craziness: managing multiple working spheres", Proceedings of the SIGCHI conference on Human factors in computing systems, ACM, p. 113-120.

Goodwin, B. (2014), "No more email? Why companies are turning to collaboration technology", $\quad$ https://www.computerweekly.com/ezine/Computer-Weekly/Boostproductivity-with-collaboration-technology/No-more-email-Why-companies-are-turning-tocollaboration-technology 
Günther, O., Krasnova, H., Riehle, D. and Schöndienst, V. (2009), "Modeling microblogging adoption in the enterprise", Proceedings of the 15th Americas Conference on Information Systems.

Harnish, V. (2014), "Five Ways to Liberate Your Team from Email Overload", Fortune, 16 June, p. 52.

Harris, J., Ives, B., and Junglas, I. (2012), "IT consumerization:When gadgets turn into enterprise IT tools", MIS Quarterly Executive, 11(3), p.99-112.

Hayano, D. (1979). “Auto-ethnography: Paradigms, problems, and prospects", Human organization, 38(1), p. 99-104.

Huber, G. and Daft, R. (1987), “The Information Environments of Organizations”, In: F. K. Jablin and L. L. Putnam (eds.), Handbook of Organizational Communication. Sage, Newbury Park, CA, p. 130-164.

Isaac, H., Kalika, M. and Charki, N. B. (2008), "An empirical investigation of e-mail use versus face-to-face meetings: Integrating the Napoleon effect perspective", Communications of the Association for Information Systems, 22(1), p. 502-509.

Jackson, T., Dawson, R. and Wilson, D. (1999), "Improving the Communications Process: The costs and effectiveness of email compared with traditional media", Fourth International Conference on Software Process Improvement Research, Education and Training, British Computer Society, INSPIRE'99, Crete, September, pp 167-178.

Jackson, T. W., Dawson, R. and Wilson, D. (2003), "Understanding email interaction increases organizational productivity", Communications of the ACM, 46(8), p. 80-84.

Janseen, R. and De Poot, H. (2006), "Information overload: why some people seem to suffer more than others", Proceedings of the 4th Nordic conference on Human-computer interaction: changing roles. ACM, p. 397-400.

Kalika, M., Boukef, N., and Isaac, H. (2007), "La théorie du millefeuille et l'usage des TIC dans l'entreprise", Revue Française de Gestion, 172(3), p. 117-129.

Kaplan, A. M. and Haenlein, M. (2010), "Users of the world, unite! The challenges and opportunities of Social Media”, Business Horizons, 53(1), p. 59-68.

Kietzmann, J. H., Hermkens, K., McCarthy, I. P. and Silvestre, B. S. (2011), "Social media? Get serious! Understanding the functional building blocks of social media", Business horizons, 54(3), p. 241-251.

Köffer, S., Anlauf, L., Ortbach, K., and Niehaves, B. (2015a), "The intensified blurring of boundaries between work and private life through IT consumerization", 23rd European Conference on Information Systems (ECIS) proceedings, Münster, Germany.

Köffer, S., Ortbach, K., Junglas, I., Niehaves, B., and Harris, J. (2015b), "Innovation through BYOD? - The influence of IT consumerization on individual IT innovation behavior", Business \& Information Systems Engineering, 57(6), p. 363-375.

Konstant, T. and Taylor, M. (2009), "Overcoming Information Overload", Hodder and Stoughton.

Kraut, R. E., Attewell, P. and Kiesler, I. S. (1997), "Media use in a global corporation: Electronic mail and organizational knowledge" in Culture of the Internet, S. Kiesler (ed.), Lawrence Erlbaum Associates Inc., New York, p. 323-342. 
Laval, C. (2015), "Du "zéro email" à la "social collaboration"”, Journal du Net. http://www.journaldunet.com/solutions/expert/60798/du--zero-email--a-la--socialcollaboration.shtml

Leclercq-Vandelannoitte A., (2015), "Managing BYOD: How do organizations incorporate user-driven IT innovations?”, Information Technology and People, 28(1), p. 2-33.

Leclercq-Vandelannoitte A. and Bertin E., (2018), "From sovereign IT governance to liberal IT governmentality: A Foucauldian analogy", European Journal of Information Systems, 27(3), p. 326-346.

Lee, J.Y., Panteli, N, Bülow, AM, and Hsu, C. (2018) "Email adaptation for conflict handling: A case study of cross-border inter-organisational partnership in East Asia", Information Systems Journal. 28(2), p. 318-339.

Legifrance (2016), article 55, Loi $\mathrm{n}^{\circ}$ 2016-1088 du 8 août 2016 relative au travail, à la modernisation du dialogue social et à la sécurisation des parcours professionnels https://www.legifrance.gouv.fr/eli/loi/2016/8/8/2016-1088/jo/article_55

Leonardi, P. M., Huysman, M. and Steinfield, C. (2013), "Enterprise social media: Definition, history, and prospects for the study of social technologies in organizations", Journal of Computer-Mediated Communication, 19(1), p. 1-19.

Li, C. and Bernoff, J. (2011), "Groundswell: Winning in a World Transformed by Social Technologies", Harvard Business Press, Boston.

Lin, B., Zagalsky, A., Storey, M.A., and Serebrenik, A. (2016), "Why Developers Are Slacking Off: Understanding How Software Teams Use Slack", CSCW'16 Proceedings of the 19th ACM Conference on Computer Supported Cooperative Work and Social Computing Companion, ACM, New York, NY, USA, 333-336.

Maan, J. (2012), “A Connected Enterprise - Transformation Through Mobility and Social Networks", International Journal of Managing Information Technology, 4(3), p. 89-96.

Mackay, W. E. (1988), "More than just a communication system: diversity in the use of electronic mail", Proceedings of the 1988 ACM conference on Computer-supported cooperative work. ACM, p. 344-353.

Mankins, M. (2017), "Collaboration Overload Is a Symptom of a Deeper Organizational Problem", Harvard Business Review, March 27.

Markus, L. (1994), "Electronic Mail as a Medium of Managerial Choice", Organization Science, 5(4), p. 502-527.

Martin, A. and Van Bavel, R. (2013), "Assessing the Benefits of Social Networks for Organizations", Joint Research Centre of the European Commission.

Mathiesen, P. and Fielt, E. (2013), "Enterprise Social Networks: A Business Model Perspective", Melbourne, ACIS.

Mazmanian, M., Orlikowsi, W. J. and Yates, J. (2013), "The Autonomy Paradox: The Implications of Mobile Devices for Knowledge professionals", Organization Science, 24(5), p. 1-21.

McAfee, A. (2009), "Enterprise 2.0: New Collaborative Tools for Your Organization's Toughest Challenges", McGraw-Hill Professional, Boston. 
McKeen, J. D. and Smith, H. A. (2004), "Developments in Practice XIII Electronic Communications: Strategies for Coping with the Deluge", Communications of the Association for Information Systems, 13(1), p. 167-176.

McKinsey Global Institute (2012), "The social economy: Unlocking value and productivity through social technologies", McKinsey and Company.

Metcalfe, B. (2013), "Metcalfe's Law after 40 Years of Ethernet”, Computer, 46(12) p. 26-31.

Miles A.M., and Huberman B.M. (1994), Analyse des Données Qualitatives, Recueil de Nouvelles Méthodes, De Boeck Université, Bruxelles.

Miller, M., Marks, A. and DeCoulode, M. (2011), "Social software for business performance The missing link in social software: Measurable business performance improvements", Deloitte Center for the Edge.

Mlaiki, A., Walsh, I. \& Kalika, M. (2017), "Why do we continue using social networking sites? The giving loop that feeds computer-mediated social ties", Systèmes d'information \& management, 22(2), p. 5-47.

Mungly, I. and Singh, A. (2012), "Understanding the Effect of Information Overload on Teleworkers", International Conference and Exhibition of new technologies: Problems of management in the real economy: challenges of modernization.

Oettl, C.A., Beck, K., Raufer, F.M., Priglmeir, A.T., Böhm, M., and Krcmar, H. (2018), “Zero Email initiative: a critical review of Change Management during the introduction of Enterprise Social Networks", Journal of Information Technology Teaching Cases, 8(2), p. 172-183.

Orlikowski, W. J., Yates, J., Okamura, K. and Fujimoto, M. (1995), "Shaping Electronic Communication: The Metastructuring of Technology in the Context of Use", Organization science, 6(4), p. 423-444.

Orsys (2017), "A quand la (vraie) fin de l'e-mail ?" http://blogs.orsys.fr/informatique/index.php/2017/01/a-quand-la-vraie-fin-de-le-mailmessagerie-email/

Osterman, M. (2008), “The Need to Unify Your Business Information”, Osterman Research, Washington;

Osterman, M. (2014a), "Evolving toward the next phase of email", Osterman Research, Washington.

Osterman, M. (2014b), "Managing Content in Enterprise Social Networks", Osterman Research: Washington.

Pascal, A., Aldebert, B. and Rouziès, A. (2018), "Les méthodes mixtes en systèmes d'information : enjeux épistémologiques et méthodologiques", Systèmes d'information \& management, 23(3), p. 99-126.

Pillet J-C, and Carillo K.D.A. (2016), "Email-free collaboration: An exploratory study on the formation of new work habits among knowledge workers", International Journal of Information Management, 36(1), p. 113-125.

Poinsot, T., Duport, F., Champloix, S. and Japiot, G. (2010), "Du collaboratif au social: l'avènement de la conversation ", Documentaliste - Science de l'Information, 47(3), p. 26-37.

Renaud, K., Ramsay, J. and Hair, M. (2006), “"You've got e-mail!"... shall I deal with it now? Electronic mail from the recipient's perspective", International Journal of Human-Computer Interaction, 21(3), p. 313-332. 
Rice, R. E. (1987), "Computer-mediated communication and organizational innovation", Journal of communication, 37(4), p. 65-94.

Richter, A., Heidemann, J., Klier, M. and Behrendt, S. (2013), "Success Measurement of Enterprise Social Networks", Proceedings 11th International Conference on Wirtschaftsinformatik. Leipzig: ECIS.

Riemer, K., Overfeld, P., Scifleet, P. and Richter, A. (2012), "Oh, SNEP! The Dynamics of Social Network Emergence-the case of Capgemini Yammer", Business Information Systems Working Paper Series.

Sarbaugh-Thompson, M. and Feldman, M. S. (1998), "Electronic mail and organizational communication: Does saying "Hi” really matter?", Organization Science, 9(6), p. 685-698.

Schwabel, D. (2014), "Gen Y and Gen Z Global Workplace Expectations Study". http://millennialbranding.com/2014/geny-genz-global-workplace-expectations-study/

Shenk, D. (1998), "Data smog: Surviving the information glut", Harper, San Francisco.

Shipilov, A. and Crawford, R. J. (2015). "How One Company Reduced Email by 64\%", Harvard Business Review. https://hbr.org/2015/06/how-one-company-reduced-email-by-64

Shirish, A., Boughzala, I. and Srivastava, S.C. (2016), "Adaptive use of social networking applications in contemporary organizations: examining the motivations of Gen Y cohorts", International Journal of Information Management, 36(6), p. 1111-1123.

Silic, M., A. Back, and D. Silic. (2015), "Teaching Case-Email: From Zero to Hero-The Beginning of The End?", Journal of Information Technology Teaching Cases, 5, p. 84-91.

Silva, F. and Ben Ali, A. (2010), "Emergence du travail collaboratif: Nouvelles Formes d'Organisation du Travail", Management \& Avenir, 6(36), p. 340-365.

Skeels, M. and Grudin, J. (2009), "When social networks cross boundaries: A case study of workplace use of Facebook and LinkedIn", Proceedings of the ACM 2009 international conference on Supporting group work, ACM, p. 95-104.

Sobotta, N., and M. Hummel. (2015), “A capacity perspective on e-mail overload: How Email use contributes to information overload", Hawaii International Conference on System Sciences $\left(\mathrm{HICSS}^{\circ}\right.$, p. 692-701.

Sobotta N. (2016), "Why Forwarded Email Threads are Hard to Read: The Email Format as an Antecedent of Email Overload", Communications of the Association for Information Systems, 39(1), p. 16-31.

Soror, A. A., Steelman, Z. R., and Limayem, M. (2012), "Discipline yourself before life disciplines you: Deficient self-regulation and mobile phone unregulated use", Hawaii International Conference on System Science, p. 849-858.

Soror, A.A., Hammer, B.I., Steelman, Z.R., Davis, F.D., and Limayem, M.M. (2015), “Good habits gone bad: Explaining negative consequences associated with the use of mobile phones from a dual-systems perspective”, Information Systems Journal, 25(3), p. 403-427.

Speier, C., Valacich, J. S. and Vessey, I. (1999), "The Influence of Task Interruption on Individual Decision Making: An Information Overload Perspective", Decision Sciences, 30(2), p. 337-360.

Spira, J. B. (2011), "Overload! How too much information is hazardous to your organization”, John Wiley and Sons, Hoboken, NJ. 
Sproull, L. and Kiesler, S. (1986), "Reducing social context cues: Electronic mail in organizational communication”, Management Science, 32(11), p. 1492-1512.

Sproull, R.F. (1991), “A lesson in electronic mail” in Connections : New ways of working in the networked organization, L. Sproull et S. Kiesler (eds), MIT press, Cambridge, p. 177-184.

Steelman, Z. Soror, A., Limayem, M., and Worrell, D. (2012), "Obsessive compulsive tendencies as predictors of dangerous mobile phone usage", AMCIS Proceedings. http://aisel.aisnet.org/amcis2012/proceedings/HCIStudies/9

Stein, E. W. and Zwass, V. (1995), “Actualizing organizational memory with information systems", Information systems research, 6(2), p. 85-117.

Stenger, T. and Coutant, A. (2015), "L'appropriation des réseaux socionumériques et les arts de l'encadrer : pour une prise en compte des rapports de force entre utilisateurs et dispositifs", Systèmes d'information \& management, 20(2), p. 89-122.

Stephens, H. (2013), "Enterprise Social Network (ESN) Vendor Comparison”, Dialogue Consulting.

Stich J-F, Tarafdar M, Stacey P, and Cooper SC. (2019), "Appraisal of Email Use as A Source of Workplace Stress: A Person-Environment Fit Approach", Journal of the Association for Information Systems. 20(2), p.132-160.

Subramaniam, N., and Nandhakumar, J. (2013), "Exploring social network interactions in enterprise systems: the role of virtual copresence", Information Systems Journal, 23(6), p.75 499.

Tarafdar, M, D'Arcy, J, Turel, O and Gupta, A. (2015), "The dark side of information technology", MIT Sloan Management Review, 56 (2), p. 61-70.

Thomas, G. F. (2006), "Reconceptualizing E-mail Overload", Journal of Business and Technical Communication, 20 (3), p. 252-287.

Tran, S. (2010), "Quand les TIC réussissent trop bien dans les organizations: le cas du courrier électronique chez les managers ”, Revue Mangagement \& Avenir, 4 (34), p. 200-215.

Tran, S. and Bertin, E. (2015), "Changing organizational models of IT departments as a result of cloud computing : proposal for a typology", Systèmes d'Information \& Management, 20(4), p. 51-87

Treem, J.W., and P.M. Leonardi. (2013), "Social media use in organizations: Exploring the affordances of visibility, editability, persistence, and association", Annals of the International Communication Association 36(1), p. 143-189.

Turban, E., Bolloju, N. and Liang, T.-P. (2011), "Enterprise Social Networking: Opportunities, Adoption, and Risk Mitigation", Journal of Organizational Computing and Electronic Commerce, 21(3), p. 202-220.

Turel, O., Serenko, A., and Giles, P. (2011), "Integrating technology addiction and use: An empirical investigation of online auction users”, MIS Quarterly, 35(4), p. 1043-1061.

Tyler, J. R. and Tang, J. C. (2003), "When can I Expect an Email Response? A Study of Rythms in Email Usage", Proceedings of the Eighth European Conference on ComputerSupported Cooperative Work. Helsinki: Kluwer Academic Publishers, p. 239-259.

Vaast, E. (2008), “Travail en réseau et réalités hiérarchiques ”, Informations sociales, 3(147), p. 48-57. 
Valacich, J., Paranka, D., George, J. and Nunamaker, J.F. (1993). "Communication Concurrency and the New Media: A New Dimension for Media Richness", Communication Research, 20(2), p. 249-276.

Van Den Hooff, B., Groot, J. and De Jonge, S. (2005), "Situational Influences on the Use of Communication Technologies A Meta-Analysis and Exploratory Study", Journal of Business Communication, 42(1), p. 4-27.

Venkatesh, V., and Davis, F. D., (2000), "A theoretical extension of the technology acceptance model: Four longitudinal field studies”, Management science, 46(2), p.186-204.

Venkatesh, V., Morris, M.G., Davis, G.B., and Davis, F.D. (2003), "User Acceptance of Information Technology: Toward a Unified View," MIS Quarterly, 27(3), p. 425-478.

Verdot, V., B. Christophe, V. Toubiana, and M. Beauvais. (2011), "Scribee ExperimentationEarly Statistics on Email Conversations" in Web Intelligence and Intelligent Agent Technology (WI-IAT), 2011 IEEE/WIC/ACM International Conference 3, p. 381-384.

Verra, L. G., Karoui, M. and Dudezert, A. (2012), “Adoption symbolique d'un Réseau Social pour entreprise: Le cas de Bouygues Construction", 17ème Colloque de l'Association Information et Management. AIM.

Wall S. (2008), "Easier said than done: Writing an autoethnography", International Journal of Qualitative Methods 7(1), p. 38-53.

Whittaker, S. and Sidner, C. (1996), "Email overload: exploring personal information management of email", Proceedings of the SIGCHI conference on Human factors in computing systems, ACM, p. 276-283.

Yin R.K. (1994), "Case Study Research: Design and Methods, Applied Social Research Methods Series", 5, 2nd Ed., Sage Publications.

Zhu, W., CHen, C. and Allen, R. B. (2006), "Visualizing an enterprise social network from email”, JCDL'06 Proceedings of the 6th ACM/IEEE-CS conference, p. 383-384.

Zubac, V. and Petrov, S. (2013), "Business Impact Of Social Networking", International Journal of Economics and Law, 3(7), p. 124-130. 
Appendix 1: Profiles of the interviewees

\begin{tabular}{|c|c|c|c|c|}
\hline COMPANY & NAME & PROFESSION & GENDER & $\begin{array}{c}\text { AGE } \\
\text { GROUP }\end{array}$ \\
\hline Banque Bonjour & Chantal & Customer relationship manager & $\mathrm{F}$ & $50 \mathrm{~s}$ \\
\hline Banque Bonjour & Bertrand & Systems architect & M & $40 \mathrm{~s}$ \\
\hline Banque Bonjour & Benjamin & Digital communication manager & M & $30 \mathrm{~s}$ \\
\hline Banque Bonjour & Florence & Customer relationship manager & $\mathrm{F}$ & $30 \mathrm{~s}$ \\
\hline Banque Bonjour & $\begin{array}{c}\text { Jean- } \\
\text { Charles }\end{array}$ & Branch manager & M & $30 \mathrm{~s}$ \\
\hline Banque Bonjour & Patrick & Customer relationship manager & M & $40 \mathrm{~s}$ \\
\hline Banque Bonjour & Rémy & Financial advisor & M & $60 \mathrm{~s}$ \\
\hline Banque Bonjour & Sandra & Business development manager & $\mathrm{F}$ & $40 \mathrm{~s}$ \\
\hline BelleCulture & Agathe & Marketing assistant & $\mathrm{F}$ & $20 \mathrm{~s}$ \\
\hline BelleCulture & Carine & Product manager & $\mathrm{F}$ & $30 \mathrm{~s}$ \\
\hline BelleCulture & Eric & Plant manager & M & $50 \mathrm{~s}$ \\
\hline BelleCulture & $\begin{array}{c}\text { Jean- } \\
\text { François }\end{array}$ & Business development manager & M & $40 \mathrm{~s}$ \\
\hline BelleCulture & Olivier & Project manager & M & $20 \mathrm{~s}$ \\
\hline BelleCulture & Sabine & Sales representative & $\mathrm{F}$ & $40 \mathrm{~s}$ \\
\hline BelleCulture & Alain & Team manager & M & $60 \mathrm{~s}$ \\
\hline PleinDénergie & Daniel & Website administrator & M & $30 \mathrm{~s}$ \\
\hline PleinDénergie & Florian & Buyer & M & $20 \mathrm{~s}$ \\
\hline PleinDénergie & $\begin{array}{l}\text { Jean- } \\
\text { Marie }\end{array}$ & Early retirement & M & $40 \mathrm{~s}$ \\
\hline PleinDénergie & Julie & Communication manager & $\mathrm{F}$ & $20 \mathrm{~s}$ \\
\hline PleinDénergie & Leos & Engineer & M & $20 \mathrm{~s}$ \\
\hline PleinDénergie & Marie & Management control director & $\mathrm{F}$ & $40 \mathrm{~s}$ \\
\hline
\end{tabular}




\begin{tabular}{|c|c|c|c|c|}
\hline PleinDénergie & Mireille & $\begin{array}{c}\text { Marketing and customer relationship } \\
\text { manager }\end{array}$ & $\mathrm{F}$ & $50 \mathrm{~s}$ \\
\hline PleinDénergie & Paul & ESN project manager & $\mathrm{M}$ & $30 \mathrm{~s}$ \\
\hline PleinDénergie & Sébastien & Auditor & $\mathrm{M}$ & $20 \mathrm{~s}$ \\
\hline
\end{tabular}

\section{Appendix 2: Thematic Coding Details}

\begin{tabular}{|c|c|c|}
\hline CATEGORY & THEME & DIMENSION \\
\hline \multirow{18}{*}{ EMAIL } & \multirow{3}{*}{ Email functions } & $\begin{array}{l}\text { Written and asynchronous } \\
\text { communication }\end{array}$ \\
\hline & & Informative tool \\
\hline & & Database \\
\hline & \multirow{3}{*}{ Email Management } & A necessity \\
\hline & & Sorting and archiving \\
\hline & & Way of keeping track \\
\hline & \multirow{4}{*}{ Email pros } & Recognized tool worldwide \\
\hline & & Rapidity \\
\hline & & Simplicity \\
\hline & & Savings \\
\hline & \multirow{3}{*}{ Email cons } & Problem of quantity and time \\
\hline & & Problem of quality \\
\hline & & Incongruous use \\
\hline & \multirow{5}{*}{ Impacts of email at work } & Loss of information \\
\hline & & Growing feeling of emergency \\
\hline & & Lower productivity \\
\hline & & Impacted interpersonal relations \\
\hline & & Multiplication of interruptions \\
\hline \multirow{9}{*}{ ESN } & \multirow{6}{*}{ ESN used functions } & IM and communication functions \\
\hline & & Information storage \\
\hline & & Wiki - blogging - forums \\
\hline & & Tagging and grouping \\
\hline & & Knowledge management \\
\hline & & Similarities with personal SNS \\
\hline & \multirow{3}{*}{ Perceived advantages } & Better collaboration \\
\hline & & Impact on communication \\
\hline & & Feeling of cross-department unity \\
\hline
\end{tabular}




\begin{tabular}{|c|c|c|}
\hline & & $\begin{array}{l}\text { Transfer of competencies and } \\
\text { information }\end{array}$ \\
\hline & \multirow{4}{*}{ Perceived disadvantages } & Impacted interpersonal relations \\
\hline & & Impact on coworkers \\
\hline & & The multiplication of tools \\
\hline & & Collaborative overload \\
\hline \multirow{14}{*}{$\begin{array}{c}\text { FACTORS } \\
\text { INFLUENCING ESN } \\
\text { USE }\end{array}$} & \multirow{6}{*}{$\begin{array}{l}\text { Factors related to the users } \\
\text { themselves }\end{array}$} & Age \\
\hline & & Job characteristics \\
\hline & & Response to change \\
\hline & & $\begin{array}{l}\text { Experience with personal SNS and } \\
\text { new technologies }\end{array}$ \\
\hline & & Email and communication habits \\
\hline & & Technology curiosity/enthusiasm \\
\hline & \multirow{3}{*}{ Factors related to the tool itself } & A tool amongst others \\
\hline & & Technical issues \\
\hline & & A tool far from actual users' needs \\
\hline & \multirow{5}{*}{$\begin{array}{l}\text { Factors related to the enterprise } \\
\text { and its context }\end{array}$} & Implementation \\
\hline & & The "snowball effect" \\
\hline & & $\begin{array}{l}\text { Managers involvement and claimed } \\
\text { strategy }\end{array}$ \\
\hline & & Industry and culture \\
\hline & & $\begin{array}{l}\text { Size and enterprise spatial } \\
\text { organization }\end{array}$ \\
\hline \multirow{10}{*}{$\begin{array}{l}\text { RELATIONS } \\
\text { RSE/EMAIL }\end{array}$} & \multirow{4}{*}{ Replacement of ESN by email } & Impact on email communication \\
\hline & & Impact on communication in general \\
\hline & & Workers feeling \\
\hline & & Brake on the replacement \\
\hline & \multirow{3}{*}{ A matter of synergy } & Redundancy of ESN and email \\
\hline & & Complementarity of ESN and email \\
\hline & & $\begin{array}{l}\text { A lack of integration between both } \\
\text { tools }\end{array}$ \\
\hline & \multirow[t]{3}{*}{ Alternatives } & Other collaborative platforms \\
\hline & & Specific collaborative tools \\
\hline & & Digital transformation strategy \\
\hline
\end{tabular}

